\title{
Influence of street setbacks on solar reflection and air cooling by reflective streets in urban canyons
}

\author{
Pablo J. Rosado, George Ban-Weiss, Arash Mohegh, Ronnen Levinson
}

\section{Abstract}

The ability of a climate model to accurately simulate the urban cooling effect of raising street albedo may be hampered by unrealistic representations of street geometry in the urban canyon. Even if the climate model is coupled to an urban canyon model (UCM), it is hard to define detailed urban geometries in UCMs. In this study, we relate simulated surface air temperature change to canyon albedo change. Using this relationship, we calculate scaling factors to adjust previously obtained surface air temperature changes that were simulated using generic canyon geometries. The adjusted temperature changes are obtained using a proposed multi-reflection urban canyon albedo model (UCAM), avoiding the need to rerun computationally expensive climate models. The adjusted temperature changes represent those that would be obtained from simulating with city-specific (local) geometries. Local urban geometries are estimated from details of the city's building stock and the city's street design guidelines. As a case study, we calculated average citywide seasonal scaling factors for realistic canyon geometries in Sacramento, California based on street design guidelines and building stock. The average scaling factors were used to adjust air temperature changes previously simulated by a Weather Research and Forecasting coupled to an urban canyon model in which streets extended from wall to wall (omitting setbacks, such as sidewalks and yards). Sacramento's scaling factors ranged from 2.70 (summer) to 3.89 (winter), demonstrating the need to consider the actual urban geometry in urban climate studies.

\section{Introduction}

Mesoscale meteorological models have been developed to predict weather and to simulate regional climates. These tools are used to understand the effects of climate change and urban growth on environmental problems in urban areas, and to develop mitigation and adaptation strategies (Chen et al. 2011). The Weather Research and Forecasting (WRF) model (Skamarock et al. 2008) is an example of such a tool used for these purposes.

Urban canyon models (UCMs) assess the geometry and the thermophysical properties of urban canyons (Best and Grimmond 2015). UCMs are used to study the influence that urban morphology, surface properties, and energy fluxes have on the local climate. Meteorological models can be coupled to UCMs to better resolve surface-atmosphere interactions in urban areas, and assess near-surface heat islands and their effect on the regional climate (Taha 1999; Chen et al. 2011). The accuracy of these coupled models depends in part on how accurate the urban morphology can be characterized in the UCM.

The WRF model can be coupled to various UCMs, each with a different level of complexity in the way it defines the urban morphology and resolves surface-atmosphere interactions. The number of parameters to model the influence of urban characteristics on the local climate also varies by UCM. When characterizing vegetative or urban surfaces, WRF defaults to a slab model, which treats the urban geometry as a flat rough surface. A WRF model can also be coupled with the single-layer urban canopy model (SLUCM) developed by Kusaka et al. (2001) and Kusaka and Kimura (2004), or the multi-layer

\section{Page 1 of 26}


urban canopy model (MLUCM) developed by Martilli et al. (2002). These two models consider the threedimensional nature of urban canyons, shadowing by canyon walls, and reflection from the canyon surfaces. Wang et al. (2013) developed an even more sophisticated urban model that incorporates vegetation within the urban canopy and can represent each canyon surface (walls, floor, and roof) as a heterogeneous surface made up of different types of sub-surfaces. Their model has been used to enhance the modeling of urban hydrological processes (e.g. those from lawns and green roofs) that affect the urban energy balance ( $\mathrm{Li}$ et al. 2014, Yang et al. 2015). However, its treatment of radiative exchange between facets of the urban canyon (wall, ground, roof, and sky) assumes that all sub-surfaces within a facet share the same view factors. For example, if the ground contains a street flanked by setbacks, such as sidewalks or lawns, the sky view factor of each setback would be assumed to be equal to the sky view factor of the street.

Accurately representing the heterogeneous nature of cities in mesoscale models is challenging (Vahmani and Ban-Weiss 2016). In many urban regions, urban planning data and remotely sensing images are used to create urban maps that classify the urban region into different land-use types. The United States Geological Survey (USGS) National Land Cover Database (NLCD) provides such maps, and describes urban regions with three different land-use categories: low-intensity residential, high-intensity residential, and industrial/commercial (Homer et al. 2011). WRF defines default urban canyon parameters for these three urban land-use categories (Chen et al. 2011); however, the urban canyon parameters can be changed by the user. The canyon geometry used by the model for a particular grid cell is then chosen from the NLCD land-use category that best matches the land cover type of the grid cell. The parameters that describe canyons include geometric dimensions (wall height, street width, and roof width); surface albedos; and thermal surface properties (see Table 1 in Chen et al. 2011). WRF can also be configured to use canyon geometries from the National Urban Database and Access Portal Tool (NUDAPT; Ching et al. 2009), but this database characterizes only a few scattered regions.

63

Cool pavements are one of several technologies that can be used to increase urban albedo and cool cities. WRF/urban canyon models can be used to study how increasing the albedo of pavements decreases convective heating of the urban air and thus decreases surface air temperature ${ }^{1}$ [Mohegh et al. (submitted)]. However, current urban parameterizations in climate models do not represent canyon geometry in sufficient detail to allow assessment of influence of pavement albedo on air temperature. First, these parameterizations generally define the street extending from wall to wall and do not permit definition of setbacks between the street and the wall. (Setbacks are the portions of the canyon floor that lie between the street and the canyon wall, such as sidewalks and front yards.) Second, the default street widths defined in these systems may not accurately represent the streets in actual cities. Third, even if urban parameterization in the climate model were sufficiently detailed, is hard to develop data describing realistic urban geometries. Hence, when a WRF/urban canyon model is used to investigate the influence on urban climate of the widespread adoption of "cool" (highly reflective) streets, the results need to be scaled to represent realistic urban geometries.

Cities have a quantifiable relationship between air temperature change and canyon albedo change [Mohegh et al. (submitted)]. Thus, changes in canyon geometry and/or surface albedo alter the canyon albedo, which may in turn affect the air temperature. Assuming other atmospheric parameters like wind flow, vertical and horizontal mixing, and turbulence kinetic energy (TKE) remain constant, the current

\footnotetext{
${ }^{1}$ The surface air temperature (hereafter, "air temperature") described here is a diagnostic variable that aims to predict the air temperature two meters above the surface. Due to the complexities of urban terrain and physics parameterizations used in urban models, this variable does not truly represent air temperature at $2 \mathrm{~m}$ above the ground (Li et al. 2014). Instead, it can be understood as a diagnostic air temperature near the top of the urban canopy.
} 
study relates between changes to canyon albedo and changes to simulated air temperature changes. This permits scaling of climate simulation results to canyon geometries that differ from those modeled. We present a method for estimating factors for scaling air temperature changes obtained from modeling cool streets with a WRF/urban canyon model to those changes expected for more realistic canyons. The advantage of this method is that existing climate model results quantifying the sensitivity of surface air temperature change to changes in canyon or grid cell albedo can be adjusted without the need to rerun the computationally expensive climate model.

Scaling factors are estimated by comparing the canyon albedo in the modeled geometry to that of the realistic geometry. Many UCMs have been developed in the last five decades. Since these models generally define surface albedos and thermal surface properties, they can be used to estimate canyon albedo. Let the designation " $N$-reflection" indicate that the model tracks each ray of light through up to $N$ reflections from canyon surfaces; any light that strikes a canyon surface after the $N^{\text {th }}$ reflection is considered to be absorbed. Terjung and Louis (1973) presented the Urban Shortwave Model with the intention of simulating urban absorption of solar radiation. Their scheme treats the U-shape part of the canyon as an infinite strip having a uniform canyon floor. The work by Terjung and Louis considers the orientation of the canyon and solar position and is a one-reflection model. More recently, Tsangrassoulis and Santamouris (2003) developed a one-reflection canyon albedo model which considers the directional reflectance of windows. The Urban Surface Albedo model developed by Arnfield (1988) was one of the first to consider the multiple reflection effect within an urban canyon. Similar calculations of multiple reflections were also applied in the Albedo Calculation Model developed by Chimklai et al. (2004), and in the urban energy balance models presented by Masson (2000) and by Harman et al. (2004).

102

All the models mentioned so far treat the canyon floor as a homogeneous surface of uniform albedo, assigning the same albedo to the street and its setbacks (if any). Fortuniak (2008) developed an urban canyon albedo model (UCAM) that slices the floor and walls into small segments and can assign a different albedo to each segment. This lets it apply to some floor segments the street albedo and to other floor segments the setback albedo. The Fortuniak UCAM model can be used for any canyon orientation, and considers multiple reflections between the canyon surfaces.

Although the Fortuniak UCAM could be used to estimate scaling factors, we propose a similar, but simpler model that treats each wall as a uniform surface and tracks up to three reflections. In the proposed UCAM, the canyon floor is composed of a central street and surrounding setbacks. We will show that estimates of canyon albedo calculated with the proposed UCAM agree well with those calculated with the Fortuniak UCAM, especially for canyons with height-to-width ratios less than unity.

This paper summarizes the physics behind the proposed UCAM, then introduces the concept of "canyon transmittance," which can be interpreted as the transmittance of sunlight from canyon ceiling to street to canyon ceiling. We then calculate scaling factors as the ratio of canyon transmittances (transmittance from canyon of interest to that of canyon used in climate model). Scaling factors can be used to adjust air temperature changes obtained from a climate model that used generic canyon geometries to what would be obtained from using realistic canyon geometries. Finally, we present a case study that uses details of building stock and street design guidelines to estimate seasonal citywide scaling factors for the 121 city of Sacramento. 


\subsection{Proposed Urban Canyon Albedo Model}

124 The proposed three-reflection UCAM calculates the amount of radiant solar power per unit of canyon 125 length $[\mathrm{W} / \mathrm{m}]$ (hereafter, "flux"; symbol J) that flows downward through the canyon ceiling. The model 126 computes as a function of canyon geometry, surface albedo, and solar position the flux that is reflected 127 from canyon surfaces-walls, setbacks, and street-and exits through the ceiling. Canyon albedo is 128 computed as the ratio of upward to downward flux through the canyon ceiling.

\section{$129 \quad 2.1 .1$ Canyon geometry}

130 The proposed UCAM defines the canyon geometry as shown in Figure 1. Surface 1 is the canyon floor, while surface 2 is the canyon ceiling; floor width $w_{1}$ equals ceiling width $w_{2}$. The canyon floor includes a central street (dashed gray line) and two setbacks of equal width (dashed green lines). The floor is divided into $N$ small segments of equal width $w_{0}$, with any particular segment referred to as surface 0 . Based on location, each segment is identified as part of the street or part of a setback. partially shaded at times. Surfaces $3 u$ and $4 u$ refer to the unshaded section of each wall, with heights $h_{3 \mathrm{u}}$ and $h_{4 \mathrm{u}}$, respectively.

138 Surfaces 5 and 6 are the canyon's light sources. Surface 5 (sun) is the source of beam (a.k.a. direct) sunlight. Surface 6 (sky) is the source of diffuse sunlight.

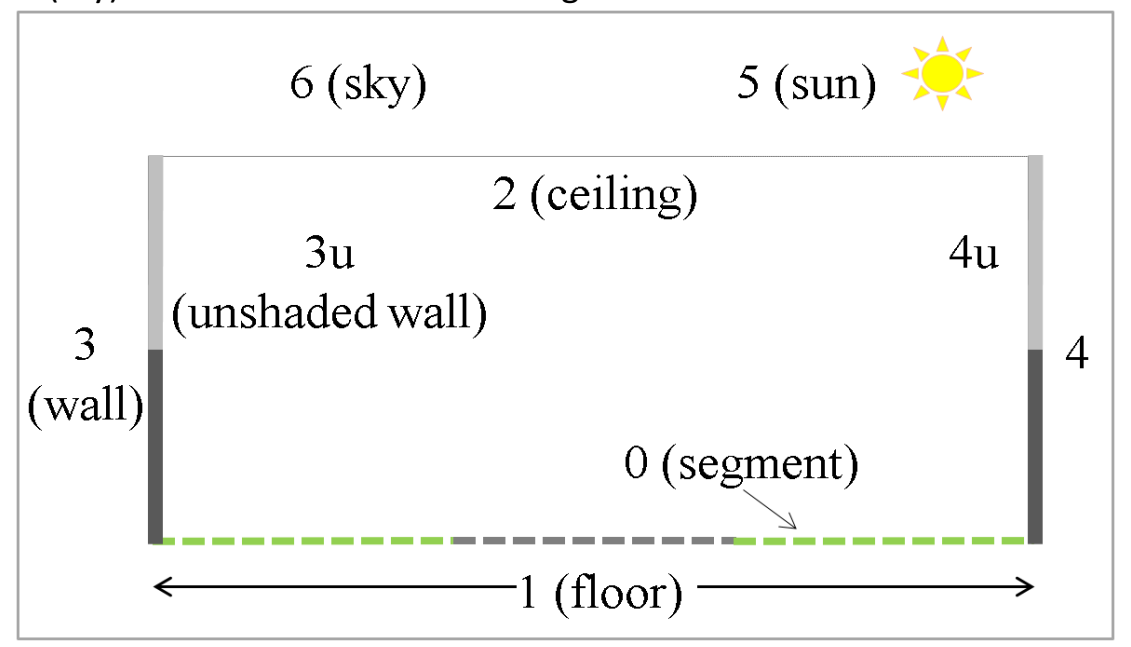

140 Figure 1. Elements of the urban canyon (surfaces $0-4$ ) and its light sources (surfaces 5 and 6).

\section{$141 \quad 2.1 .2 \quad$ Solar fluxes}

142 The proposed UCAM calculates all fluxes that enter the canyon and escape through the ceiling after no more than three reflections. To calculate the fluxes, the model uses the sun position, canyon orientation, albedo and dimension of canyon elements, and hourly beam and diffuse horizontal solar 145 irradiances.

146 The fluxes that escape the canyon after the first, second, or third reflection are listed in Table 1, Table 2, 147 and Table 3, respectively. In the flux formulas, $\rho_{\mathrm{X}}$ is the albedo (solar reflectance) of surface $\mathrm{X} . J_{2}$ is 
the diffuse sky flux entering through the ceiling, while $J_{5 \rightarrow 0}, J_{5 \rightarrow 3 u}$, and $J_{5 \rightarrow 4 u}$ are the beam solar fluxes to a sunlit floor segment, to the sunlit portion of the left wall, and to the sunlit portion of the right wall, respectively.

151 The dimensions of the canyon elements are used to calculate view factors. A view factor (a.k.a. 152 configuration factor or shape factor) $F_{\mathrm{X} \rightarrow \mathrm{Y}}$ to surface $\mathrm{Y}$ from surface $\mathrm{X}$ is the fraction of radiant energy 153 leaving surface $X$ that is intercepted by surface $Y$.

154 The fluxes that strike a floor segment (surface 0) are calculated independently for each floor segment. 155 According to its location, the segment is assigned the albedo of either the setback or the street. The 156 proposed three-reflection UCAM computes the total upward flux as the sum of all the fluxes listed in 157 Table 1 through Table 3, including the fluxes that strike each floor segment. Canyon albedo is then 158 computed as the ratio of upward to downward flux through the canyon ceiling. Appendix A gives 159 additional details on how to calculate the solar fluxes and the canyon albedo. Appendix B details 160 calculation of the view factors.

161 Table 1. Fluxes that escape the canyon after the first reflection.

\begin{tabular}{|l|l|}
\hline \multicolumn{1}{|c|}{ Path } & \multicolumn{1}{|c|}{ Formula } \\
\hline ceiling (2) to left wall (3) to ceiling (2) & $J_{2} \cdot F_{2 \rightarrow 3} \cdot \rho_{3} \cdot F_{3 \rightarrow 2}$ \\
\hline ceiling (2) to right wall (4) to ceiling (2) & $J_{2} \cdot F_{2 \rightarrow 4} \cdot \rho_{4} \cdot F_{4 \rightarrow 2}$ \\
\hline ceiling (2) to segment (0) to ceiling (2) & $J_{2} \cdot F_{2 \rightarrow 0} \cdot \rho_{0} \cdot F_{0 \rightarrow 2}$ \\
\hline sun (5) to sunlit left wall (3u) to ceiling (2) & $J_{5 \rightarrow 3 \mathrm{u}} \cdot \rho_{3} \cdot F_{3 \mathrm{u} \rightarrow 2}$ \\
\hline sun (5) to sunlit right wall (4u) to ceiling (2) & $J_{5 \rightarrow 4 \mathrm{u}} \cdot \rho_{4} \cdot F_{4 \mathrm{u} \rightarrow 2}$ \\
\hline sun (5) to segment (0) to ceiling (2) & $J_{5 \rightarrow 0} \cdot \rho_{0} \cdot F_{0 \rightarrow 2}$ \\
\hline
\end{tabular}

162 Table 2. Fluxes that escape the canyon after the second reflection.

\begin{tabular}{|l|l|}
\hline \multicolumn{1}{|c|}{ Path } & \multicolumn{1}{|c|}{ Formula } \\
\hline ceiling (2) to left wall (3) to right wall (4) to ceiling (2) & $J_{2} \cdot F_{2 \rightarrow 3} \cdot \rho_{3} \cdot F_{3 \rightarrow 4} \cdot \rho_{4} \cdot F_{4 \rightarrow 2}$ \\
\hline ceiling (2) to left wall (3) to segment (0) to ceiling (2) & $J_{2} \cdot F_{2 \rightarrow 3} \cdot \rho_{3} \cdot F_{3 \rightarrow 0} \cdot \rho_{0} \cdot F_{0 \rightarrow 2}$ \\
\hline ceiling (2) to right wall (4) to left wall (3) to ceiling (2) & $J_{2} \cdot F_{2 \rightarrow 4} \cdot \rho_{4} \cdot F_{4 \rightarrow 3} \cdot \rho_{3} \cdot F_{3 \rightarrow 2}$ \\
\hline ceiling (2) to right wall (4) to segment (0) to ceiling (2) & $J_{2} \cdot F_{2 \rightarrow 4} \cdot \rho_{4} \cdot F_{4 \rightarrow 0} \cdot \rho_{0} \cdot F_{0 \rightarrow 2}$ \\
\hline ceiling (2) to segment (0) to left wall (3) to ceiling (2) & $J_{2} \cdot F_{2 \rightarrow 0} \cdot \rho_{0} \cdot F_{0 \rightarrow 3} \cdot \rho_{3} \cdot F_{3 \rightarrow 2}$ \\
\hline ceiling (2) to segment (0) to right wall (4) to ceiling (2) & $J_{2} \cdot F_{2 \rightarrow 0} \cdot \rho_{0} \cdot F_{0 \rightarrow 4} \cdot \rho_{4} \cdot F_{4 \rightarrow 2}$ \\
\hline sun (5) to sunlit left wall (3u) to right wall (4) to ceiling (2) & $J_{5 \rightarrow 3 \mathrm{u}} \cdot \rho_{3} \cdot F_{3 \mathrm{u} \rightarrow 4} \cdot \rho_{4} \cdot F_{4 \rightarrow 2}$ \\
\hline sun (5) to sunlit left wall (3u) to segment (0) to ceiling (2) & $J_{5 \rightarrow 3 \mathrm{u}} \cdot \rho_{3} \cdot F_{3 \mathrm{u} \rightarrow 0} \cdot \rho_{0} \cdot F_{0 \rightarrow 2}$ \\
\hline sun (5) to sunlit right wall (4u) to left wall (3) to ceiling (2) & $J_{5 \rightarrow 4 \mathrm{u}} \cdot \rho_{4} \cdot F_{4 \mathrm{u} \rightarrow 3} \cdot \rho_{3} \cdot F_{3 \rightarrow 2}$ \\
\hline sun (5) to sunlit right wall (4u) to segment (0) to ceiling (2) & $J_{5 \rightarrow 4 \mathrm{u}} \cdot \rho_{4} \cdot F_{4 \mathrm{u} \rightarrow 0} \cdot \rho_{0} \cdot F_{0 \rightarrow 2}$ \\
\hline sun (5) to segment (0) to left wall (3) to ceiling (2) & $J_{5 \rightarrow 0} \cdot \rho_{0} \cdot F_{0 \rightarrow 3} \cdot \rho_{3} \cdot F_{3 \rightarrow 2}$ \\
\hline sun (5) to segment (0) to right wall (4) to ceiling (2) & $J_{5 \rightarrow 0} \cdot \rho_{0} \cdot F_{0 \rightarrow 4} \cdot \rho_{4} \cdot F_{4 \rightarrow 2}$ \\
\hline
\end{tabular}

163 Table 3. Fluxes that escape the canyon after the third reflection.

\begin{tabular}{|c|c|}
\hline \multicolumn{1}{|c|}{ Path } & Formula \\
\hline ceiling (2) to segment (0) to left wall (3) & $J_{2} \cdot F_{2 \rightarrow 0} \cdot \rho_{0} \cdot F_{0 \rightarrow 3} \cdot \rho_{3} \cdot F_{3 \rightarrow 4} \cdot \rho_{4} \cdot F_{4 \rightarrow 2}$ \\
\hline
\end{tabular}




\begin{tabular}{|c|c|}
\hline to right wall (4) to ceiling (2) & \\
\hline $\begin{array}{l}\text { ceiling (2) to segment (0) to right wall (4) } \\
\text { to left wall (3) to ceiling (2) }\end{array}$ & $J_{2} \cdot F_{2 \rightarrow 0} \cdot \rho_{0} \cdot F_{0 \rightarrow 4} \cdot \rho_{4} \cdot F_{4 \rightarrow 3} \cdot \rho_{3} \cdot F_{3 \rightarrow 2}$ \\
\hline $\begin{array}{l}\text { ceiling (2) to segment }(0) \text { to left wall (3) } \\
\text { to segment }(0) \text { to ceiling (2) }\end{array}$ & $J_{2} \cdot F_{2 \rightarrow 0} \cdot \rho_{0} \cdot F_{0 \rightarrow 3} \cdot \rho_{3} \cdot F_{3 \rightarrow 0} \cdot \rho_{0} \cdot F_{0 \rightarrow 2}$ \\
\hline $\begin{array}{l}\text { ceiling (2) to segment }(0) \text { to right wall (4) } \\
\text { to segment }(0) \text { to ceiling (2) }\end{array}$ & $J_{2} \cdot F_{2 \rightarrow 0} \cdot \rho_{0} \cdot F_{0 \rightarrow 4} \cdot \rho_{4} \cdot F_{4 \rightarrow 0} \cdot \rho_{0} \cdot F_{0 \rightarrow 2}$ \\
\hline $\begin{array}{l}\text { ceiling (2) to left wall (3) to right wall (4) } \\
\text { to left wall (3) to ceiling (2) }\end{array}$ & $J_{2} \cdot F_{2 \rightarrow 3} \cdot \rho_{3} \cdot F_{3 \rightarrow 4} \cdot \rho_{4} \cdot F_{4 \rightarrow 3} \cdot \rho_{3} \cdot F_{3 \rightarrow 2}$ \\
\hline $\begin{array}{l}\text { ceiling (2) to left wall (3) to right wall (4) } \\
\text { to segment (0) to ceiling (2) }\end{array}$ & $J_{2} \cdot F_{2 \rightarrow 3} \cdot \rho_{3} \cdot F_{3 \rightarrow 4} \cdot \rho_{4} \cdot F_{4 \rightarrow 0} \cdot \rho_{0} \cdot F_{0 \rightarrow 2}$ \\
\hline $\begin{array}{l}\text { ceiling (2) to left wall (3) to segment (0) } \\
\text { to left wall (3) to ceiling (2) }\end{array}$ & $J_{2} \cdot F_{2 \rightarrow 3} \cdot \rho_{3} \cdot F_{3 \rightarrow 0} \cdot \rho_{0} \cdot F_{0 \rightarrow 3} \cdot \rho_{3} \cdot F_{3 \rightarrow 2}$ \\
\hline $\begin{array}{l}\text { ceiling (2) to left wall (3) to segment (0) } \\
\text { to right wall (4) to ceiling (2) }\end{array}$ & $J_{2} \cdot F_{2 \rightarrow 3} \cdot \rho_{3} \cdot F_{3 \rightarrow 0} \cdot \rho_{0} \cdot F_{0 \rightarrow 4} \cdot \rho_{4} \cdot F_{4 \rightarrow 2}$ \\
\hline $\begin{array}{l}\text { ceiling (2) to right wall (4) to left wall (3) } \\
\text { to right wall (4) to ceiling (2) }\end{array}$ & $J_{2} \cdot F_{2 \rightarrow 4} \cdot \rho_{4} \cdot F_{4 \rightarrow 3} \cdot \rho_{3} \cdot F_{3 \rightarrow 4} \cdot \rho_{4} \cdot F_{4 \rightarrow 2}$ \\
\hline $\begin{array}{l}\text { ceiling (2) to right wall (4) to left wall (3) } \\
\text { to segment (0) to ceiling (2) }\end{array}$ & $J_{2} \cdot F_{2 \rightarrow 4} \cdot \rho_{4} \cdot F_{4 \rightarrow 3} \cdot \rho_{3} \cdot F_{3 \rightarrow 0} \cdot \rho_{0} \cdot F_{0 \rightarrow 2}$ \\
\hline $\begin{array}{l}\text { ceiling (2) to right wall (4) to segment (0) } \\
\text { to left wall (3) to ceiling (2) }\end{array}$ & $J_{2} \cdot F_{2 \rightarrow 4} \cdot \rho_{4} \cdot F_{4 \rightarrow 0} \cdot \rho_{0} \cdot F_{0 \rightarrow 3} \cdot \rho_{3} \cdot F_{3 \rightarrow 2}$ \\
\hline $\begin{array}{l}\text { ceiling (2) to right wall (4) to segment (0) } \\
\text { to right wall (4) to ceiling (2) }\end{array}$ & $J_{2} \cdot F_{2 \rightarrow 4} \cdot \rho_{4} \cdot F_{4 \rightarrow 0} \cdot \rho_{0} \cdot F_{0 \rightarrow 4} \cdot \rho_{4} \cdot F_{4 \rightarrow 2}$ \\
\hline $\begin{array}{l}\text { sun (5) to segment (0) to left wall (3) } \\
\text { to right wall (4) to ceiling (2) }\end{array}$ & $J_{5 \rightarrow 0} \cdot \rho_{0} \cdot F_{0 \rightarrow 3} \cdot \rho_{3} \cdot F_{3 \rightarrow 4} \cdot \rho_{4} \cdot F_{4 \rightarrow 2}$ \\
\hline $\begin{array}{l}\text { sun (5) to segment }(0) \text { to right wall (4) } \\
\text { to left wall (3) to ceiling (2) }\end{array}$ & $J_{5 \rightarrow 0} \cdot \rho_{0} \cdot F_{0 \rightarrow 4} \cdot \rho_{4} \cdot F_{4 \rightarrow 3} \cdot \rho_{3} \cdot F_{3 \rightarrow 2}$ \\
\hline $\begin{array}{l}\text { sun }(5) \text { to segment }(0) \text { to left wall ( } 3) \\
\text { to segment }(0) \text { to ceiling }(2)\end{array}$ & $J_{5 \rightarrow 0} \cdot \rho_{0} \cdot F_{0 \rightarrow 3} \cdot \rho_{3} \cdot F_{3 \rightarrow 0} \cdot \rho_{0} \cdot F_{0 \rightarrow 2}$ \\
\hline $\begin{array}{l}\text { sun }(5) \text { to segment }(0) \text { to right wall (4) } \\
\text { to segment }(0) \text { to ceiling }(2)\end{array}$ & $J_{5 \rightarrow 0} \cdot \rho_{0} \cdot F_{0 \rightarrow 4} \cdot \rho_{4} \cdot F_{4 \rightarrow 0} \cdot \rho_{0} \cdot F_{0 \rightarrow 2}$ \\
\hline $\begin{array}{l}\text { sun (5) to sunlit left wall ( } 3 \mathrm{u}) \text { to right wall (4) } \\
\text { to left wall (3) to ceiling }(2)\end{array}$ & $J_{5 \rightarrow 3 \mathrm{u}} \cdot \rho_{3} \cdot F_{3 \mathrm{u} \rightarrow 4} \cdot \rho_{4} \cdot F_{4 \rightarrow 3} \cdot \rho_{3} \cdot F_{3 \rightarrow 2}$ \\
\hline $\begin{array}{l}\text { sun }(5) \text { to sunlit left wall }(3 \mathrm{u}) \text { to right wall (4) } \\
\text { to segment }(0) \text { to ceiling }(2)\end{array}$ & $J_{5 \rightarrow 3 \mathrm{u}} \cdot \rho_{3} \cdot F_{3 \mathrm{u} \rightarrow 4} \cdot \rho_{4} \cdot F_{4 \rightarrow 0} \cdot \rho_{0} \cdot F_{0 \rightarrow 2}$ \\
\hline $\begin{array}{l}\text { sun (5) to sunlit left wall ( } 3 \mathrm{u}) \text { to segment }(0) \\
\text { to left wall (3) to ceiling }(2)\end{array}$ & $J_{5 \rightarrow 3 \mathrm{u}} \cdot \rho_{3} \cdot F_{3 \mathrm{u} \rightarrow 0} \cdot \rho_{0} \cdot F_{0 \rightarrow 3} \cdot \rho_{3} \cdot F_{3 \rightarrow 2}$ \\
\hline $\begin{array}{l}\text { sun (5) to sunlit left wall ( } 3 \mathrm{u}) \text { to segment }(0) \\
\text { to right wall (4) to ceiling }(2)\end{array}$ & $J_{5 \rightarrow 3 \mathrm{u}} \cdot \rho_{3} \cdot F_{3 \mathrm{u} \rightarrow 0} \cdot \rho_{0} \cdot F_{0 \rightarrow 4} \cdot \rho_{4} \cdot F_{4 \rightarrow 2}$ \\
\hline $\begin{array}{l}\text { sun (5) to sunlit right wall }(4 \mathrm{u}) \text { to left wall (3) } \\
\text { to right wall }(4) \text { to ceiling }(2)\end{array}$ & $J_{5 \rightarrow 4 \mathrm{u}} \cdot \rho_{4} \cdot F_{4 \mathrm{u} \rightarrow 3} \cdot \rho_{3} \cdot F_{3 \rightarrow 4} \cdot \rho_{4} \cdot F_{4 \rightarrow 2}$ \\
\hline $\begin{array}{l}\text { sun }(5) \text { to sunlit right wall }(4 \mathrm{u}) \text { to left wall (3) } \\
\text { to segment }(0) \text { to ceiling }(2)\end{array}$ & $J_{5 \rightarrow 4 \mathrm{u}} \cdot \rho_{4} \cdot F_{4 \mathrm{u} \rightarrow 3} \cdot \rho_{3} \cdot F_{3 \rightarrow 0} \cdot \rho_{0} \cdot F_{0 \rightarrow 2}$ \\
\hline $\begin{array}{l}\text { sun }(5) \text { to sunlit right wall }(4 \mathrm{u}) \text { to segment }(0) \\
\text { to left wall (3) to ceiling }(2)\end{array}$ & $J_{5 \rightarrow 4 \mathrm{u}} \cdot \rho_{4} \cdot F_{4 \mathrm{u} \rightarrow 0} \cdot \rho_{0} \cdot F_{0 \rightarrow 3} \cdot \rho_{3} \cdot F_{3 \rightarrow 2}$ \\
\hline $\begin{array}{l}\text { sun (5) to sunlit right wall }(4 \mathrm{u}) \text { to segment }(0) \\
\text { to right wall }(4) \text { to ceiling }(2)\end{array}$ & $J_{5 \rightarrow 4 \mathrm{u}} \cdot \rho_{4} \cdot F_{4 \mathrm{u} \rightarrow 0} \cdot \rho_{0} \cdot F_{0 \rightarrow 4} \cdot \rho_{4} \cdot F_{4 \rightarrow 2}$ \\
\hline
\end{tabular}

\subsubsection{Canyon transmittance}

165 Canyon transmittance $\tau_{\text {canyon }}$ is defined as the ratio of (a) the increase in sunlight reflected through the canyon ceiling upon raising the albedo of a street in the canyon, to (b) the increase in sunlight reflected upon raising the albedo of the same street not in a canyon. It can be interpreted as the transmittance of sunlight from canyon ceiling to street to canyon ceiling. 
Let $\tau_{\text {down }}$ represent the fraction of downward solar flux (downflux) from the sun and sky that travels from ceiling to floor, from ceiling to wall to street, or from ceiling to wall to opposite wall to street. Similarly, let $\tau_{\text {up }}$ represent the fraction of sunlight reflected from the street that travels from street to

172 ceiling, from street to wall to ceiling, or from street to wall to opposite wall to ceiling.

173 Neglecting reflection of light from street to wall to floor, and from street to wall to opposite wall to 174 floor, increasing by $\Delta \rho_{\text {st }}$ the albedo of a street of width $w_{\text {st }}$ inside a canyon will increase the upward 175 solar flux (upflux) through the canyon ceiling by

$$
\Delta J_{\text {up,inside }}=I_{\mathrm{g}} \tau_{\text {down }} w_{\text {st }} \Delta \rho_{\text {st }} \tau_{\text {up }} .
$$

176 where $I_{\mathrm{g}}\left[\mathrm{W} / \mathrm{m}^{2}\right]$ is the global horizontal solar irradiance. Increasing by $\Delta \rho_{\mathrm{r}}$ the albedo of the same 177 street outside a canyon will increase its upflux by

$$
\Delta J_{\text {up }, \text { outside }}=I_{\mathrm{g}} w_{\mathrm{st}} \Delta \rho_{\mathrm{st}} \cdot
$$

178 Therefore

$$
\tau_{\text {canyon }} \equiv \frac{\Delta J_{\text {up,inside }}}{\Delta J_{\text {up,outside }}}=\frac{I_{\mathrm{g}} \tau_{\text {down }} w_{\text {st }} \Delta \rho_{\text {st }} \tau_{\text {up }}}{I_{\mathrm{g}} w_{\text {st }} \Delta \rho_{\text {st }}}=\tau_{\text {down }} \tau_{\text {up }}
$$

179

Canyon transmittance should approach unity as canyon height approaches zero, and should never exceed unity.

The proposed UCAM is used to calculate the upward flux leaving the canyon, $J_{\text {up }}$, as a function of street albedo. $J_{\text {up }}$ is obtained by summing all fluxes listed in Table 1, Table 2, and Table 3, including those intercepted by each floor segment. We can then obtain the increase in upflux $\Delta J_{\text {up,inside }}$ upon increasing by $\Delta \rho_{\text {st }}$ the albedo of a street in the canyon by subtracting $J_{\text {up }}$ calculated with the original road albedo from $J_{\text {up }}$ calculated with the modified street albedo:

$$
\Delta J_{\text {up,inside }}=J_{\text {up }}\left(\rho_{\text {st, modified }}\right)-J_{\text {up }}\left(\rho_{\text {st, original }}\right) .
$$

$J_{\text {up }}\left(\rho_{\text {st,original }}\right)$ is the upward flux leaving the canyon calculated with the original street albedo, and $J_{\text {up }}\left(\rho_{\text {st,modified }}\right)$ is that calculated with the modified pavement albedo. The modified street albedo is obtained as

$$
\rho_{\mathrm{st}, \text { modified }}=\rho_{\mathrm{st}, \text { original }}+\Delta \rho_{\mathrm{st}}
$$

\subsubsection{Scaling factor}

Changing the geometry and surface albedos of an urban canyon may perturb various local atmospheric parameters such as wind flow, vertical and horizontal mixing, and TKE. These parameters may affect the surface and temperatures. Assuming the atmospheric parameters remain constant, we expect changes Mohegh et al. (submitted)]. To elaborate, the reduction in the air temperature is proportional to the 
reduction in the canyon's solar heat gain, which in turn is proportional to the decrease in the canyon's solar absorptance. The reduction in canyon solar absorptance is the same as the increase in canyon albedo. Hence, the reduction in air temperature is proportional to the increase in flux reflected from the canyon ( $\Delta J_{\text {up,inside }}$ ), or simply

$$
\Delta T \propto \Delta J_{\text {up,inside }}
$$

Climate models can be used to predict the reduction in air temperature upon increasing the street albedo in a canyon. However, this change in air temperature applies only to a city with the canyon geometry defined in the climate model, and must be adjusted to describe air temperature changes that will occur in a city with different canyon geometries.

To illustrate, assume that the climate model was used to obtain the air temperature change from modifying the street albedo in a city composed of narrow canyons (canyons with no setbacks). The narrow-canyon temperature change $\Delta T_{\mathrm{n}}$ may need to be scaled to estimate temperature changes $\Delta T_{\mathrm{w}}$ from wide canyons (canyons with setbacks), where subscripts $n$ and $w$ refer to narrow and wide canyons, respectively. Assuming $\Delta T$ is proportional to $\Delta J_{\text {up,inside }}$, we define a canyon reflection scaling factor $\sigma_{\mathrm{n} \rightarrow \mathrm{w}}$ to relate the air temperature changes in a wide canyon to those in a narrow canyon:

$$
\Delta T_{\mathrm{w}}=\sigma_{\mathrm{n} \rightarrow \mathrm{w}} \Delta T_{\mathrm{n}}
$$

where

$$
\sigma_{\mathrm{n} \rightarrow \mathrm{w}} \equiv \frac{\Delta T_{\mathrm{w}}}{\Delta T_{\mathrm{n}}}=\frac{\Delta J_{\text {up,inside, } \mathrm{w}}}{\Delta J_{\text {up,inside, } \mathrm{n}}} .
$$

The increase in canyon-reflected flux $\Delta J_{\text {up,inside }}$ upon raising street albedo by $\Delta \rho_{\text {st }}$ is proportional to $\tau_{\text {canyon. }}$ If the wide and narrow canyons have the same street width and the same increase in street albedo, then

$$
\Delta J_{\text {up,outside,w }}=\Delta J_{\text {up,outsiden }}=I_{\mathrm{g}} w_{\text {st }} \Delta \rho_{\text {st }}
$$

and the scaling factor equals the ratio of canyon transmittance:

$$
\sigma_{\mathrm{n} \rightarrow \mathrm{w}}=\frac{\Delta J_{\text {up,inside, } \mathrm{w}}}{\Delta J_{\text {up,inside, } \mathrm{n}}}=\frac{\tau_{\text {canyon,w }} \Delta J_{\text {up,outside, } \mathrm{w}}}{\tau_{\text {canyon, } \mathrm{n}} \Delta J_{\text {up,outside, }}}=\frac{\tau_{\text {canyon, } \mathrm{w}}}{\tau_{\text {canyon, } \mathrm{n}}} .
$$

Citywide scaling factor. The shapes of urban canyons can vary between cities and within a city. However, they can be estimated from the city's street design standards and building stock. First, several wide canyons are defined, each with geometries that represent a particular city region and dimensions that follow the street design guidelines of that region. Next, we compute a canyon reflection scaling factor for each wide canyon to relate the air temperature changes in the wide canyon to those in a narrow canyon. Each building of the city is then mapped to one of the newly defined wide canyons. Finally, a citywide scaling factor $\left(\sigma_{\mathrm{n} \rightarrow \overline{\mathrm{w}}}\right)$ can be calculated as the average of the scaling factors of each wide canyon weighted by the number of buildings assigned to each wide canyon. The citywide scaling factor can be used in Eq. (7) to scale the changes in air temperature of a city modeled entirely with the narrow canyon to the city composed of the more realistic wide canyons. 


\subsection{Methodology}

226 In addition to the proposed three-reflection UCAM, we generated one-reflection and two-reflection versions of the proposed UCAM. Each version (one-, two-, or three-reflection) of the proposed UCAM was compared to the Fortuniak UCAM (Fortuniak 2008). Fortuniak calculated albedos for north-south $(\mathrm{N}-\mathrm{S})$ and east-west $(\mathrm{E}-\mathrm{W})$ canyons with the ratio of building height $(H)$ to floor (street + setbacks) width $(W), H / W$, ranging from 0.1 to 8 . He assigned to the floor and walls an albedo of 0.40 , and computed solar irradiances following the Global Radiation Model proposed by Davies et al. (1975). We applied the three versions of the proposed UCAM to canyon geometries previously analyzed by Fortuniak, using the same floor albedo, wall albedo, solar positions, and irradiances.

The proposed UCAM and the Fortuniak UCAM were compared by calculating the daily mean difference (proposed UCAM - Fortuniak UCAM) in daily-mean canyon albedo, and the root-mean-square difference (RMSD) between the instantaneous canyon albedos for each $\mathrm{H} / \mathrm{W}$ value, canyon orientation, and proposed UCAM version.

\subsection{Results}

Figure 2 compares for $\mathrm{N}-\mathrm{S}$ canyons (panels $\mathrm{a}-\mathrm{C}$ ) and $\mathrm{E}-\mathrm{W}$ canyons (panels $\mathrm{d}-\mathrm{f}$ ) the instantaneous canyon albedos calculated by Fortuniak (2008) to the one-reflection (panels a and d), two-reflection (panels $b$ and $\mathrm{e}$ ), and three-reflection (panels $\mathrm{c}$ and $\mathrm{f}$ ) versions of the proposed UCAM. Each panel shows instantaneous canyon albedos for $\mathrm{H} / \mathrm{W}$ values of $0.1,0.5,1,4$, and 8 . Table 4 lists by $\mathrm{H} / \mathrm{W}$ value and canyon orientation (N-S, E-W) the differences (proposed UCAM - Fortuniak UCAM) in daily-mean canyon albedo, calculated using Eq. (A-18). Table 4 also reports the root-mean-square differences (RMSDs) between the instantaneous canyon albedos estimated with each version of the proposed UCAM and those estimated by Fortuniak UCAM.

For each $\mathrm{H} / \mathrm{W}$ value, all instantaneous albedos calculated with the three versions of the proposed UCAM are lower than the albedo generated by the Fortuniak UCAM. These differences in albedo between the Fortuniak UCAM and the proposed UCAM increase with H/W.

The albedos obtained with the one-reflection version of the proposed UCAM are significantly lower than those obtained by Fortuniak, especially for $\mathrm{H} / \mathrm{W}>0.1$. For $\mathrm{H} / \mathrm{W}$ equal to 0.1 , the one-reflection version gives a daily mean albedo that is 0.013 (E-W) and 0.017 (N-S) lower than the estimate from Fortuniak UCAM, with RMSDs of 0.019 (N-S) and 0.014 (E-W). However, for H/W equal to 1 , the daily mean canyon albedo from the one-reflection version was about 0.046 lower than the estimate from Fortuniak UCAM for N-S and E-W canyons; RMSD was 0.046 for N-S and E-W canyons.

The albedo estimates with the proposed UCAM improved with the two- and three-reflection versions. As an example, the albedos obtained for $\mathrm{H} / \mathrm{W} \leq 1$ with the three-reflection version match very well with Fortuniak's albedos. The mean RMSDs were small, ranging from $0.002(H / W=0.1)$ to $0.007(H / W=1)$.

All of the canyons defined in Section 5.1 .1 have $\mathrm{H} / \mathrm{W}<1$ (Table 6); the single-family home canyon has a $\mathrm{H} / \mathrm{W}$ of 0.18 . The city's most common building type is single-family home (Public Records 2015). Therefore, the two- and three-reflection versions of the proposed UCAM are suitable for estimating the albedo of the canyons we defined for Sacramento. However, we use the three-reflection version for all remaining analyses in this study because is slightly more accurate than the two-reflection version. 
Fortuniak UCAM and proposed
UCAM (one-reflection version)

(a)

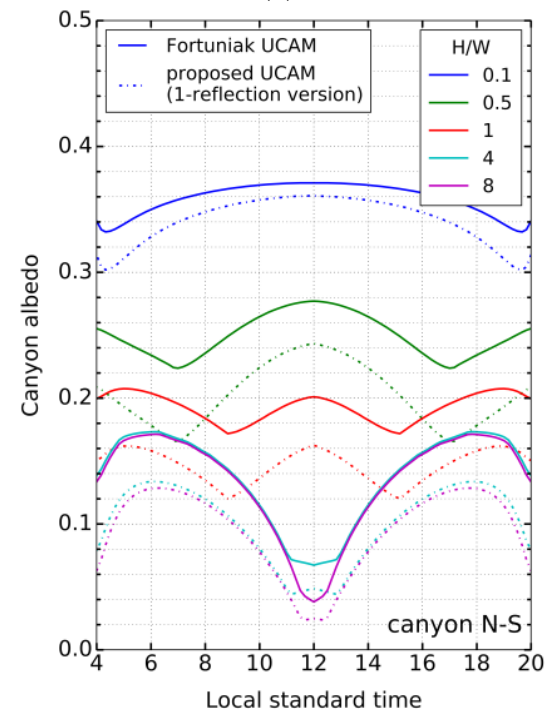

(d)

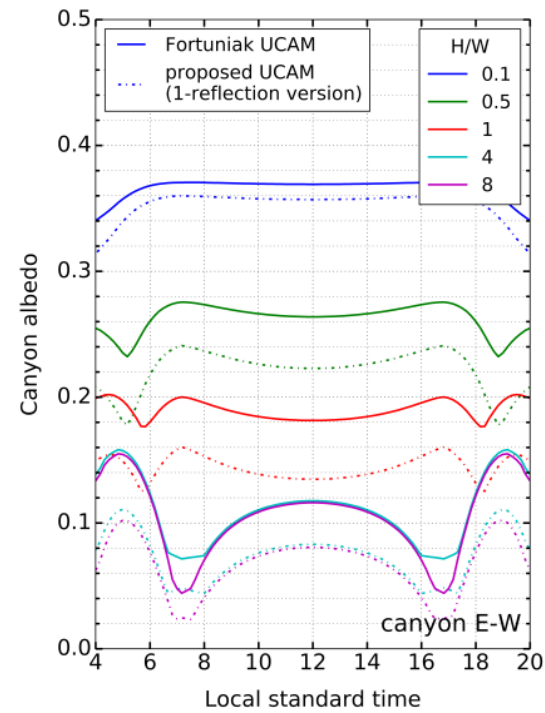

Fortuniak UCAM and proposed UCAM (two-reflection version)

(b)

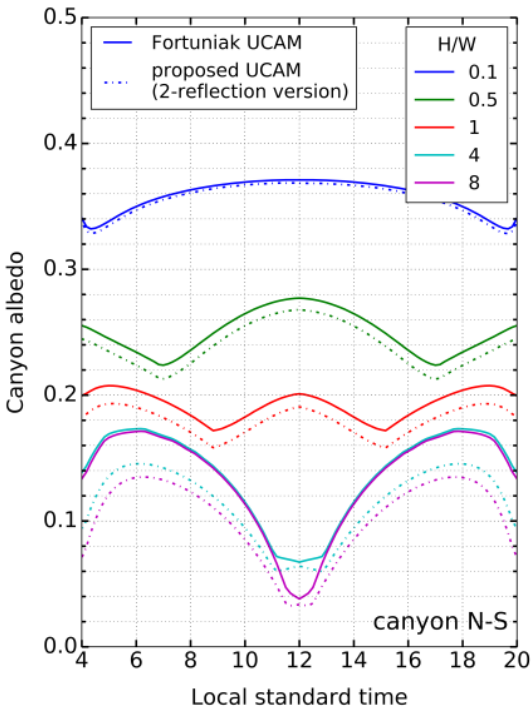

(e)

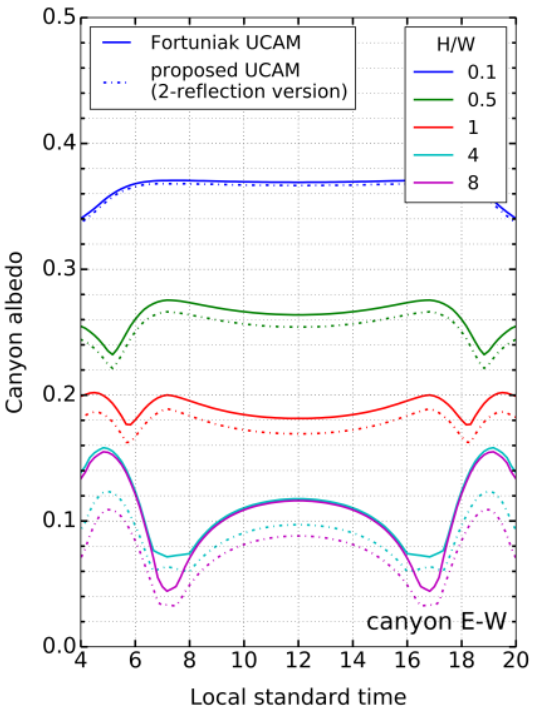

Fortuniak UCAM and proposed UCAM (three-reflection version)

(c)

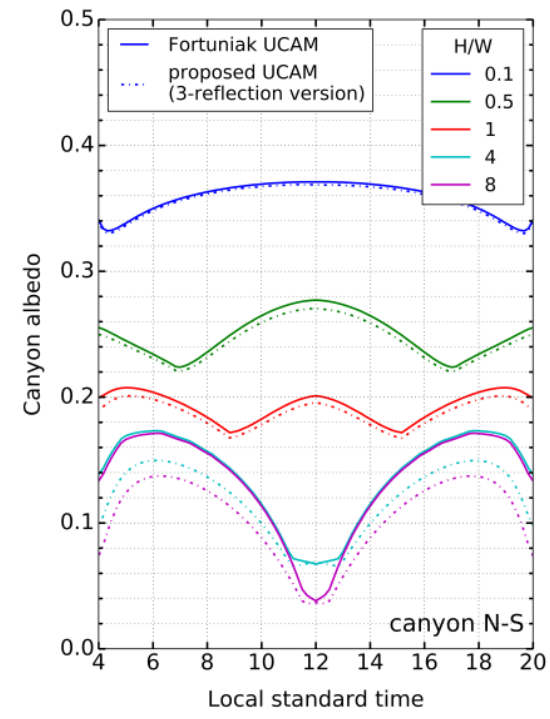

(f)

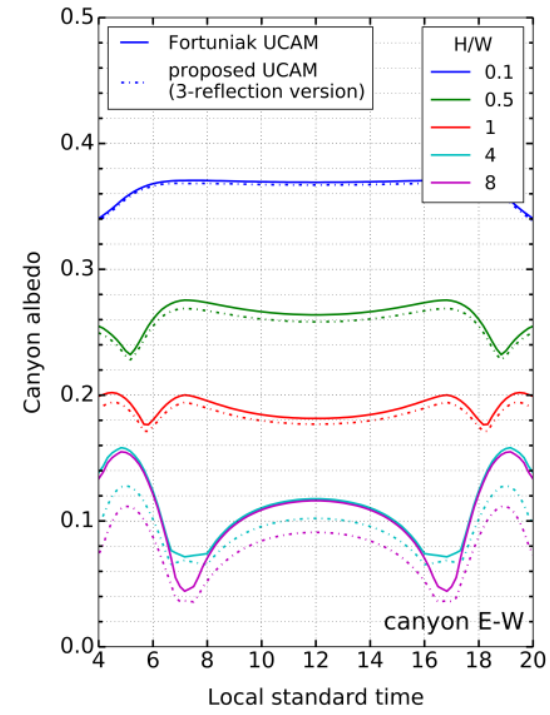

Figure 2. Instantaneous canyon albedos calculated with the Fortuniak UCAM (solid lines) are compared to canyon albedos calculated with the one-reflection (panels a and d), two-reflection (panels $b$ and e), and three-reflection (panels c and f) versions of the proposed UCAM (dotted lines). The albedo of each canyon surface is $0.40 ; \mathrm{H} / \mathrm{W}$ ranges from 0.1 to 8 . Canyon is evaluated at latitude $55^{\circ} \mathrm{N}$ on June 22 . The canyons are oriented $\mathrm{N}-\mathrm{S}$ (panels a-c) and E-W (panels d-f).

Table 4. Differences (proposed UCAM - Fortuniak UCAM) in daily-mean canyon albedo as well as root-meansquare differences (RMSDs) of the instantaneous canyon albedos plotted in Figure 2. Daily-mean differences and RMSDs are listed for the one-, two-, and three-reflection versions of the proposed UCAM against the Fortuniak UCAM.

\begin{tabular}{|c|c|c|c|c|c|}
\hline \multirow{2}{*}{ H/W } & \multirow{2}{*}{\begin{tabular}{l} 
Maximum number \\
\multirow{2}{*}{ of reflections }
\end{tabular}} & \multicolumn{2}{|c|}{$\begin{array}{c}\text { Daily-mean difference (proposed UCAM } \\
\text { - Fortuniak UCAM) in canyon albedo }\end{array}$} & \multicolumn{2}{|c|}{$\begin{array}{c}\text { RMSD in instantaneous } \\
\text { canyon albedo }\end{array}$} \\
\cline { 3 - 6 } & & N-S canyon & E-W canyon & N-S canyon & E-W canyon \\
\hline \multirow{2}{*}{0.1} & 1 & -0.013 & -0.017 & 0.019 & 0.014 \\
\cline { 2 - 6 } & 2 & -0.003 & -0.003 & 0.003 & 0.003 \\
\hline
\end{tabular}




\begin{tabular}{|c|c|c|c|c|c|}
\hline & 3 & -0.002 & -0.002 & 0.002 & 0.002 \\
\hline \multirow{3}{*}{0.5} & 1 & -0.042 & -0.048 & 0.048 & 0.042 \\
\cline { 2 - 6 } & 2 & -0.010 & -0.010 & 0.010 & 0.010 \\
\hline \multirow{3}{*}{1} & 3 & -0.007 & -0.007 & 0.007 & 0.007 \\
\cline { 2 - 6 } & 1 & -0.046 & -0.046 & 0.046 & 0.046 \\
\cline { 2 - 6 } & 2 & -0.013 & -0.013 & 0.013 & 0.013 \\
\hline \multirow{3}{*}{4} & 3 & -0.007 & -0.007 & 0.007 & 0.007 \\
\cline { 2 - 6 } & 1 & -0.037 & -0.038 & 0.038 & 0.038 \\
\hline \multirow{3}{*}{8} & 2 & -0.022 & -0.024 & 0.026 & 0.024 \\
\cline { 2 - 6 } & 3 & -0.018 & -0.020 & 0.022 & 0.020 \\
\cline { 2 - 6 } & 1 & -0.039 & -0.040 & 0.041 & 0.041 \\
\hline
\end{tabular}

\section{Demonstrating calculation of scaling factors}

\section{$276 \quad 4.1$ Methodology}

277 We compare by season the increase in canyon-reflected flux upon raising street albedo in a narrow 278 canyon (no setbacks) $\Delta J_{\text {up,inside, }}$, to that upon raising the street albedo in a wide canyon (with 279 setbacks) $\Delta J_{\text {up,inside,w }}$. The narrow canyon (hereafter, "simple narrow canyon") has a $10 \mathrm{~m}$ wide street. 280 The wide canyon (hereafter, "simple wide canyon") also has a $10 \mathrm{~m}$ wide street, plus $10 \mathrm{~m}$ wide 281 setbacks. Each canyon has $10 \mathrm{~m}$ high walls with albedo 0.20 and the street has an albedo of 0.10 . The 282 setbacks in the simple wide canyon have an albedo of 0.10 (Table 5). The street albedo was raised to 2830.40 from 0.10 to represent a scenario in which a typical low-albedo pavement like asphalt concrete is 284 treated with a reflective polymer coating. Our examples use hourly solar positions and solar irradiances 285 in Sacramento, CA near the summer solstice. The seasonal scaling factors are calculated as the ratio of $286 \Delta J_{\text {up,inside,w }}$ to $\Delta J_{\text {up,insiden }}$.

287 Table 5. Geometries of the simple narrow canyon and the simple wide canyon.

\begin{tabular}{|l|c|c|c|c|c|}
\hline Canyon version & $\begin{array}{l}\text { Wall height, } \\
\boldsymbol{H}[\mathbf{m}]\end{array}$ & $\begin{array}{l}\text { Street } \\
\text { width }[\mathbf{m}]\end{array}$ & $\begin{array}{l}\text { Setback } \\
\text { width }[\mathbf{m}]\end{array}$ & $\begin{array}{l}\text { Floor width, } \\
\boldsymbol{W}[\mathbf{m}]\end{array}$ & H/W \\
\hline simple narrow canyon & 10 & 10 & 0 & 10 & 1.00 \\
\hline simple wide canyon & 10 & 10 & 10 & 30 & 0.33 \\
\hline
\end{tabular}

\subsection{Results}

289 Figure 3 compares the increase in canyon-reflected flux upon raising street albedo to 0.40 from 0.10 in 290 the simple narrow canyon ( $\Delta J_{\text {up,insiden }}$ ) to that upon raising street albedo in the simple wide canyon ( $\left.\Delta J_{\text {up,inside, }}\right)$. The plots show seasonal canyon-reflected flux for canyons the canyons oriented $\mathrm{E}-\mathrm{W}$ and $\mathrm{N}-\mathrm{S}$. A representative day of each season is obtained by calculating the hourly mean solar irradiances (global horizontal and diffuse horizontal) of 21 days around the summer and winter solstices and the 294 spring and fall equinoxes. 
(a)

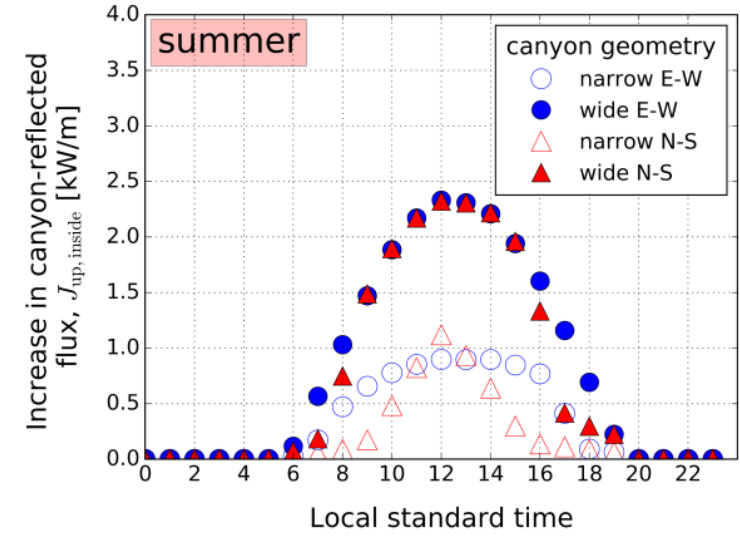

(c)

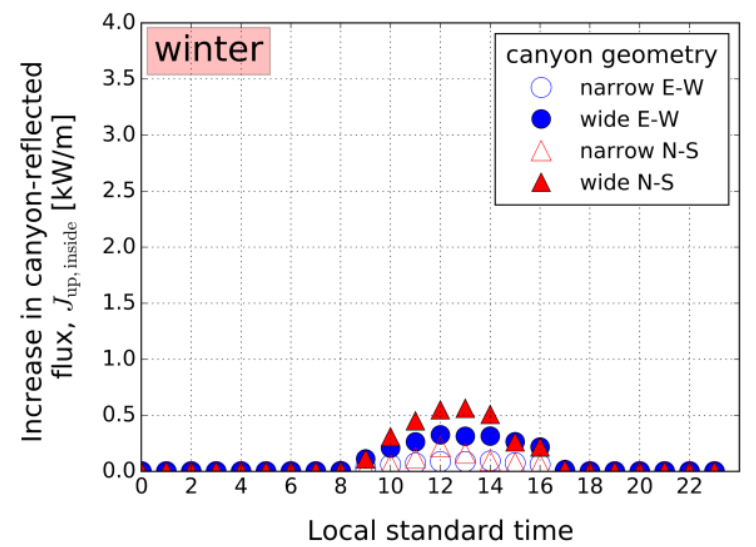

(b)

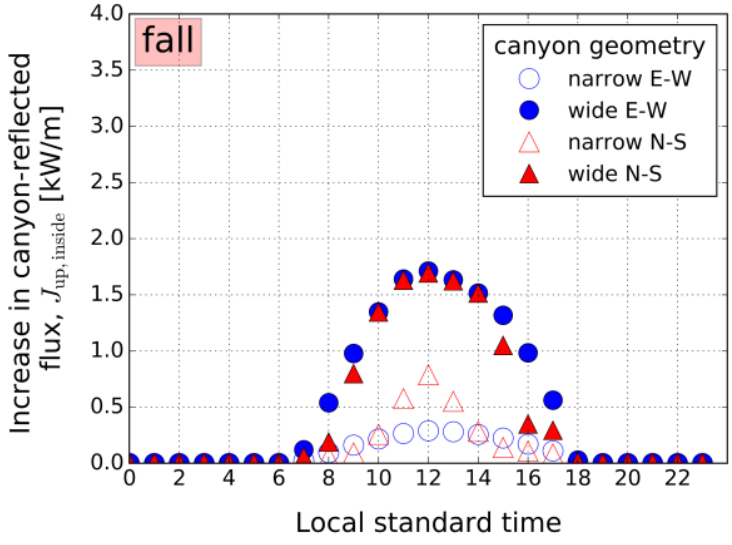

(d)

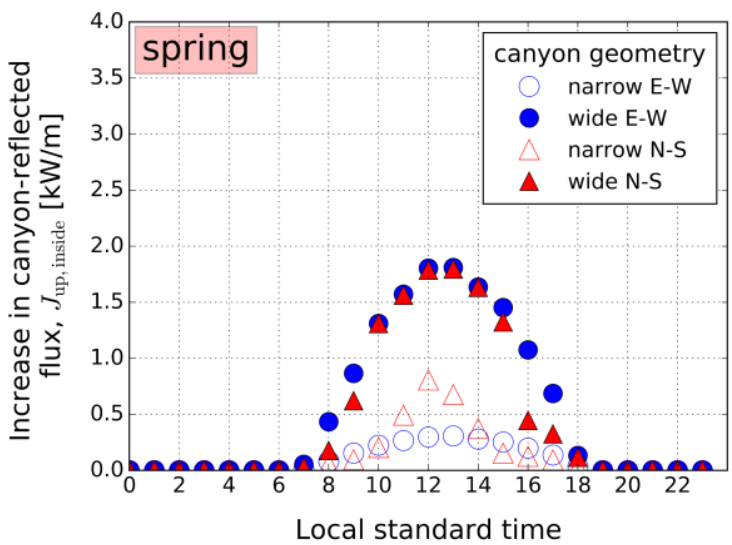

Figure 3. Hourly increases in canyon-reflected flux $[\mathrm{W} / \mathrm{m}]$ when raising street albedo to 0.40 from 0.10 for representative days in (a) summer (b) fall, (c) winter, and (d) spring.

The difference in canyon-reflected flux when modifying the street albedo varies by canyon orientation and season (Figure 3). However, when the street is in the simple wide canyon, it is able to reflect out of the canyon much more solar flux than when it is in the simple narrow canyon. The daily mean increases in canyon-reflected flux in the simple narrow canyon $\Delta J_{\text {up,inside, }}$, averaged between $\mathrm{E}-\mathrm{W}$ and $\mathrm{N}-\mathrm{S}$ canyons, are $269 \mathrm{~W} / \mathrm{m}$ (representative summer day), $106 \mathrm{~W} / \mathrm{m}$ (fall), $30.0 \mathrm{~W} / \mathrm{m}$ (winter), and $112 \mathrm{~W} / \mathrm{m}$ (spring). These differences in canyon-reflected flux represent the average of $\mathrm{E}-\mathrm{W}$ and $\mathrm{N}-\mathrm{S}$ canyons. For the simple wide canyon, the differences in flux were $778 \mathrm{~W} / \mathrm{m}$ (summer), $478 \mathrm{~W} / \mathrm{m}$ (fall), $105 \mathrm{~W} / \mathrm{m}$ (winter), and $499 \mathrm{~W} / \mathrm{m}$ (spring). Thus, the ratios of $\Delta J_{\text {up,inside, }}$ to $\Delta J_{\text {up,inside, }}$ give 2.90 (summer), 4.52 (fall), 3.52 (winter), and 4.45 (spring). These ratios are the factors $\sigma_{\mathrm{n} \rightarrow \mathrm{w}}$ for scaling air temperatures from the simple narrow canyon to the simple wide canyon.

\section{Calculating citywide scaling factors using the proposed UCAM}

\subsection{Methodology}

We present the method for scaling changes in a city's air temperatures obtained from modeling cool streets with a WRF/urban canyon model. First, we defined a narrow canyon with dimensions of the highdensity residential land-use category from United States Geological Survey (USGS) National Land Cover 
Database, or NLCD (Homer et al. 2011). Second, we used the dimensions of 10 building prototypes and the street design guidelines of Sacramento to define 10 realistic wide canyons. After calculating the seasonal scaling factors for each wide canyon, we obtained the seasonal citywide scaling factors weighted by the number of buildings in Sacramento mapped to each wide canyon.

\subsubsection{Defining canyon geometries}

NLCD narrow canyon

The three urban land-use categories defined in the NLCD are "low-intensity residential", "high-intensity residential", and "industrial \& commercial". These three categories are the default options in WRF for defining urban canyons, and each omits setbacks (canyon floor width equals street width). Additionally, the street widths in these default canyons vary between $8.3 \mathrm{~m}$ (low-intensity residential) to $10 \mathrm{~m}$ (industrial \& commercial). These street widths are narrower than the widths of large portions of city streets (Sacramento Street Design Standards 2009). Since single-family homes and multi-family buildings are the most common type of buildings in Sacramento (Public Records 2015), we defined an "NLCD narrow canyon" based on the NLCD high-intensity residential canyon geometry (Table 6).

\section{Realistic wide canyons}

Ten "wide" canyons were defined to represent actual wall, street, and setback dimensions obtained from building prototypes and from the street design guidelines of Sacramento. Wall heights in two residential scenarios-single-family home and apartment building-were obtained from the building models provided by the United States Department of Energy (DOE) Building Energy Codes Program (PNNL 2014). The wall heights of eight commercial scenarios were obtained from DOE's commercial reference building models (Deru et al. 2011).

The street widths vary according to street design standards. Each building prototype was mapped to a street type depending on the building use and size. We obtained the dimensions and lane configurations of each street type for the city of Sacramento (Sacramento Street Design Standards 2009).

The setback widths follow street design guidelines specified by building type in the Zoning Code of (Sacramento Street Design Standards 2009).

Table 6 details the dimensions of the wide canyons. Notice that none of the canyons have a height-towidth ratio $\mathrm{H} / \mathrm{W}>1$. Wide-canyon $\mathrm{H} / \mathrm{W}$ ranges from 0.04 (retail stand-alone canyon) to 0.93 (large office canyon), with a mean of 0.25 .

342 Table 6. Dimensions for the narrow and wide canyons.

\begin{tabular}{|l|l|l|c|c|c|c|}
\hline \multirow{4}{*}{ Canyon type } & Canyon name & $\begin{array}{l}\text { Wall height, } \\
\boldsymbol{H}[\mathbf{m}]\end{array}$ & $\begin{array}{l}\text { Street } \\
\text { width [m] }\end{array}$ & $\begin{array}{l}\text { Setback } \\
\text { width [m] }\end{array}$ & $\begin{array}{l}\text { Floor width, } \\
\boldsymbol{W}[\mathbf{m}]\end{array}$ & H/W \\
\hline Narrow & NLCD narrow & 7.5 & 9.4 & 0.0 & 9.4 & 0.80 \\
\hline \multirow{5}{*}{ Wide } & Single-family home & 5.2 & 9.1 & 9.6 & 28.3 & 0.18 \\
\cline { 2 - 7 } & Apartment building & 7.8 & 9.1 & 11.1 & 31.3 & 0.25 \\
\cline { 2 - 7 } & Large hotel & 21.6 & 16.5 & 19.7 & 55.9 & 0.39 \\
\cline { 2 - 7 } & Large office & 37.5 & 16.5 & 12.0 & 40.5 & 0.93 \\
\cline { 2 - 7 } & Medium office & 11.9 & 11.0 & 11.1 & 33.2 & 0.36 \\
\cline { 2 - 7 } & Primary school & 4.0 & 9.1 & 11.1 & 31.3 & 0.13 \\
\cline { 2 - 7 } & Fast-food restaurant & 3.1 & 11.0 & 18.7 & 48.4 & 0.06 \\
\cline { 2 - 7 } & Retail stand-alone & 6.1 & 22.0 & 64.5 & 151.0 & 0.04 \\
\cline { 2 - 7 } & Strip mall retail & 5.2 & 16.5 & 18.7 & 53.9 & 0.10 \\
\cline { 2 - 7 } & Sit-down restaurant & 3.1 & 9.1 & 18.7 & 46.5 & 0.07 \\
\hline
\end{tabular}




\subsubsection{Scaling factor for city composed of the wide canyons}

344 We demonstrate the method for scaling the air temperature changes obtained from simulating an 345 albedo increase of 0.30 for Sacramento's public streets. The temperature changes were simulated using 346 WRF version 3.5.1 coupled to the single layer urban canopy model [Mohegh et al. (submitted)] in which all urban canyons were defined with the NLCD's high-intensity residential canyon type. To scale the simulated temperature changes, we use the building stock of Sacramento and assume the city is composed of the wide canyons defined in Section 5.1.1.

\section{Sacramento's building stock}

351 Sacramento's building stock was obtained from the Sacramento County Assessor office (Public Records 352 2015). The County Assessor office is responsible for the discovery and assessment of all the properties 353 within its jurisdiction. Their public records provide information for each of the properties, which include 354 location (county, city, and zip code) and property type (e.g., single-family home, office building).

All properties in the County Assessor's building stock data are classified into 63 types. We grouped and tallied the properties by type. Nearly half of the property types-e.g., vacant land, agricultural fieldswere not relevant to our study. That left 32 relevant property types. Each remaining property type was mapped to one of the wide geometry canyons to represent all the relevant buildings in Sacramento 359 (Table 7).

360 Table 7. Mapping of Sacramento's building stock to the wide canyons.

\begin{tabular}{|l|l|}
\hline $\begin{array}{l}\text { Wide canyon } \\
\text { name }\end{array}$ & Stock property types \\
\hline $\begin{array}{l}\text { Single-family } \\
\text { home }\end{array}$ & $\begin{array}{l}\text { Single family residence } \\
\text { Duplex } \\
\text { Triplex } \\
\text { Mobile home } \\
\text { Trailer park } \\
\text { Miscellaneous residential } \\
\text { Fraternal organization }\end{array}$ \\
\hline Large hotel & $\begin{array}{l}\text { Hotel } \\
\text { Motel } \\
\text { Casino } \\
\text { Hospital } \\
\text { Convalescent home }\end{array}$ \\
\hline $\begin{array}{l}\text { Retail stand- } \\
\text { alone }\end{array}$ & $\begin{array}{l}\text { Department store } \\
\text { Food store } \\
\text { Market } \\
\text { Bowling alley }\end{array}$ \\
\hline $\begin{array}{l}\text { Fast-food } \\
\text { restaurant }\end{array}$ & $\begin{array}{l}\text { Laundry } \\
\text { Dry cleaning }\end{array}$ \\
\hline Large office & $\begin{array}{l}\text { Financial building } \\
\text { Office building }\end{array}$ \\
\hline
\end{tabular}

\begin{tabular}{|l|l|}
\hline $\begin{array}{l}\text { Wide canyon } \\
\text { name }\end{array}$ & Stock property types \\
\hline $\begin{array}{l}\text { Apartment } \\
\text { building }\end{array}$ & $\begin{array}{l}\text { Multi-family dwelling (2-4 units) } \\
\text { Qulti-family residence (5+ units) } \\
\text { Timeshare } \\
\text { Condominium } \\
\text { Planned unit development (PUD) } \\
\text { Cooperative }\end{array}$ \\
\hline $\begin{array}{l}\text { Medium } \\
\text { office }\end{array}$ & $\begin{array}{l}\text { Store/office combo } \\
\text { Medical building } \\
\text { Miscellaneous commercial } \\
\text { Nursery } \\
\text { Veterinary } \\
\text { Governmental }\end{array}$ \\
\hline $\begin{array}{l}\text { Strip mall } \\
\text { retail }\end{array}$ & $\begin{array}{l}\text { Shopping center } \\
\text { Stores } \\
\text { Retail outlet }\end{array}$ \\
\hline $\begin{array}{l}\text { Sit-down } \\
\text { restaurant }\end{array}$ & $\begin{array}{l}\text { Restaurant } \\
\text { Bar } \\
\text { Food service }\end{array}$ \\
\hline $\begin{array}{l}\text { Primary } \\
\text { school }\end{array}$ & School \\
\hline
\end{tabular}

\section{1}

362

363

364

365

\section{Weighted citywide scaling factor}

The proposed UCAM was used to calculate seasonal canyon transmittance for the NLCD narrow canyon and for each wide canyon. The seasonal scaling factors for each wide canyon were then obtained as the ratios of wide canyon seasonal transmittances to NLCD narrow canyon seasonal transmittance. Finally, the seasonal citywide scaling factors $\sigma_{\mathrm{n} \rightarrow \overline{\mathrm{w}}}$ were calculated as the average of the scaling factors 
weighted by the number of buildings mapped to each wide canyon.

\subsection{Results}

\subsubsection{Comparing canyon transmittances}

The NLCD narrow canyon and the 10 realistic wide canyons were modeled for Sacramento, CA to calculate their canyon transmittance when raising the street albedo to 0.40 from 0.10 . The canyon transmittances were calculated for each season and averaged over the two orientations (Figure 4).

The seasonal canyon transmittances of the NLCD narrow canyon are 0.24 (spring), 0.33 (summer), 0.24 (fall), and 0.21 (winter). The large office canyon has very tall walls compared to the other wide canyons, and is the only wide canyon with seasonal transmittances similar to the NLCD narrow canyon. Canyon transmittances of the large office are 0.17 (spring), 0.34 (summer), 0.17 (fall), and 0.20 (winter).

The transmittances of the canyons associated with the single-family home, the two restaurants, the two retail buildings, and the primary school are 0.85 or higher. The transmittances in each of these canyons vary little between spring, summer, and fall. For the single-family home, the winter transmittance is 0.05 lower than its other seasonal transmittances; for the restaurants and retail stores, the winter transmittances are 0.01 lower than their other seasonal transmittances.

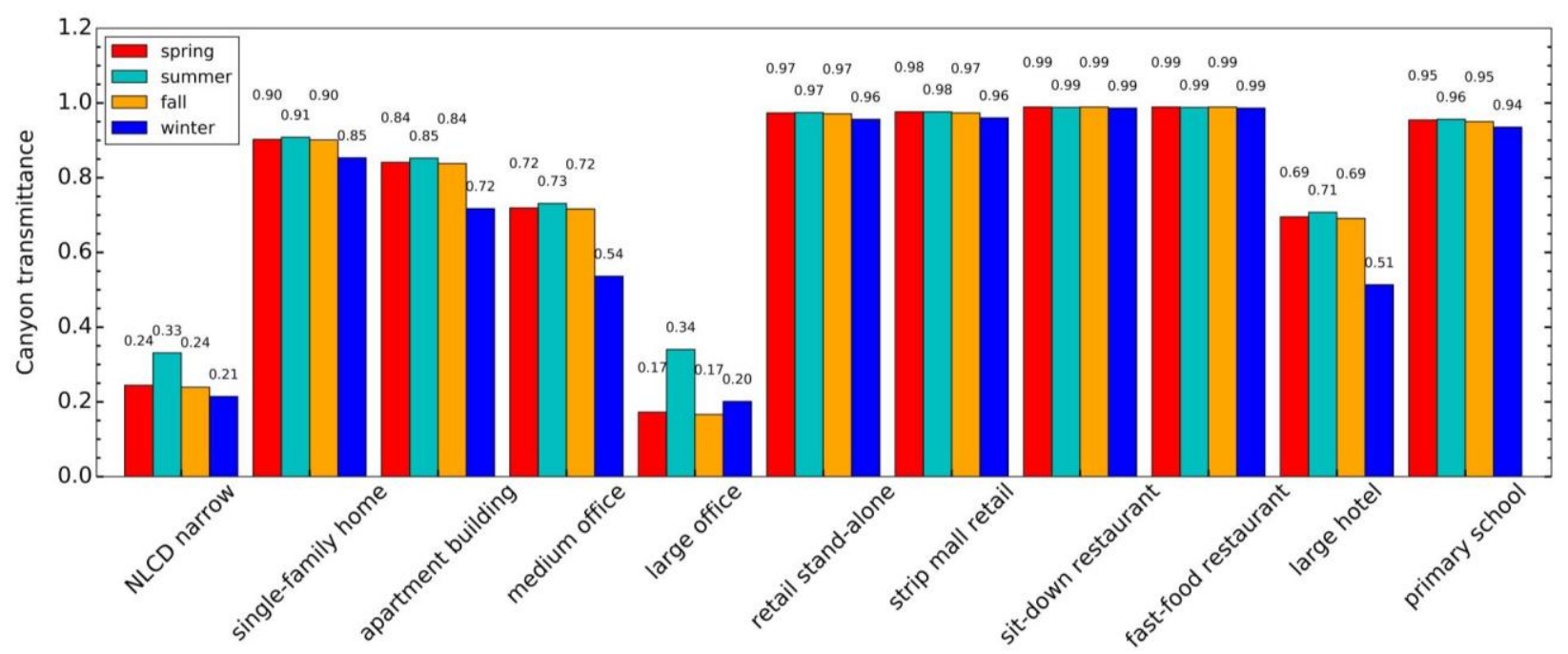

Figure 4. Seasonal transmittances of narrow canyon (first group of columns) and wide canyons (remaining groups of columns) in Sacramento.

\subsubsection{Citywide scaling factor to represent Sacramento}

Table 8 lists the seasonal scaling factors of each wide canyon as well as the number of buildings in Sacramento mapped to the wide canyons. With the exception of the large office canyon, the scaling factors were smallest for summer and largest for winter. In summer, scaling factors ranged from 1.03 (large office) to 2.98 (restaurants); in winter, scaling factors ranged from 0.94 (large office) to 4.61 (restaurants). The weighted average citywide scaling factors are 3.64 (spring), 2.70 (summer), 3.71 (fall), and 3.89 (winter).

Table 8. Seasonal scaling factors (calculated), and number of buildings (mapped) for each wide canyon.

\begin{tabular}{|l|c|c|c|c|c|}
\hline \multirow{2}{*}{ Wide canyon name } & \multicolumn{4}{|c|}{ Narrow to wide canyon scaling factor, $\sigma_{\mathrm{n} \rightarrow \mathrm{w}}$} & $\begin{array}{l}\text { Number of buildings } \\
\text { in Sacramento }\end{array}$ \\
\cline { 2 - 5 } & Spring & Summer & Fall & Winter & 202,567 \\
\hline Single-family home & 3.70 & 2.74 & 3.77 & 3.99 & \\
\hline
\end{tabular}




\begin{tabular}{|l|c|c|c|c|c|}
\hline Apartment building & 3.45 & 2.57 & 3.51 & 3.35 & 11,946 \\
\hline Large hotel & 2.85 & 2.14 & 2.89 & 2.40 & 299 \\
\hline Large office & 0.70 & 1.03 & 0.69 & 0.94 & 2,194 \\
\hline Medium office & 2.95 & 2.21 & 3.00 & 2.50 & 6,339 \\
\hline Primary school & 3.91 & 2.89 & 3.97 & 4.37 & 422 \\
\hline Fast-food restaurant & 4.05 & 2.98 & 4.14 & 4.61 & 0 \\
\hline Retail stand-alone & 3.99 & 2.94 & 4.06 & 4.47 & 187 \\
\hline Strip mall retail & 4.00 & 2.95 & 4.07 & 4.49 & 1,899 \\
\hline Sit-down restaurant & 4.05 & 2.98 & 4.14 & 4.61 & 581 \\
\hline
\end{tabular}

\section{Discussion}

\subsection{Merits of the proposed UCAM}

393 We compared the albedo of canyons with different $\mathrm{H} / \mathrm{W}$ calculated with three versions (one-reflection, 394 two-reflection, and three-reflection) of the proposed UCAM to the canyon albedos calculated by 395 Fortuniak (2008). The agreement between the Fortuniak UCAM and the proposed UCAM was weakest for the one-reflection version. The two-reflection and three-reflection versions of the proposed UCAM agreed well with the Fortuniak UCAM, especially for $\mathrm{H} / \mathrm{W} \leq 1$. We selected the three-reflection version to calculate the seasonal citywide scaling factors for Sacramento because it matched results from the Fortuniak UCAM slightly better than did the two-reflection version. The additional computations required to run the three-reflection version instead of the two-reflection version are the fluxes that escape the canyon after the third reflection (Table 3). However, executing the third-reflection version do not add significant execution time compared to that of the two-reflection version.

\subsection{Calculating canyon transmittances and scaling factors}

404 The method for calculating scaling factors was first demonstrated by comparing the change in solar flux reflected from the simple narrow canyon to that of the simple wide canyon when raising the street albedo by 0.30 . The simple wide canyon was able to reflect substantially more sunlight than the simple narrow canyon, with wide-to-narrow canyon reflected flux ratios of 2.90 in summer, 4.52 in fall, 3.52 in winter, and 4.45 in spring. These ratios are the seasonal scaling factors (discussed in Section 2.1.4) for adjusting air temperature changes from a narrow canyon to a wide canyon.

We calculated scaling factors for simulated air temperature changes obtained from modeling cool streets in Sacramento with the NLCD narrow canyon. The NLCD narrow canyon geometry represents the dimensions defined for the "high-intensity residential" land-use category described in NLCD. In Sacramento, single-family home is the predominant building type-89\% of Sacramento's building stock is single-family homes. Therefore, the weighted citywide scaling factor in each season is overwhelmingly dominated by the scaling factor of the single-family home canyon. The scaling factors of the singlefamily home canyon vary from 2.74 (summer) to 3.99 (winter). These scaling factors demonstrate that although the NLCD canyon is used to describe residential urban canyons (the most common canyon type in Sacramento), air temperature changes simulated with the NLCD canyon need to be scale between 2.74 and 3.99 times to properly represent realistic residential canyon geometries.

420 The smallest scaling factors were those for the large office canyon, which ranged from 0.70 to 1.03. These scaling factors close to unity means that the transmittances of the large office canyon are similar 422 to the NLCD narrow canyon. (The large office canyon has $37.5 \mathrm{~m}$ tall walls, $16.5 \mathrm{~m}$ wide street, $12 \mathrm{~m}$ 423 wide setbacks, and $\mathrm{H} / \mathrm{W}=0.93$.) 


\section{Summary}

425 The WRF/urban canyon model can be used to study how modifying the albedo of urban canyon surfaces changes the urban climate. However, the canyon geometries defined in these systems may not accurately describe actual urban canyon dimensions; they often define the street extending from wall to wall with no setbacks between the street and the wall, and the street width may not accurately represent the streets in actual cities. It is also challenging to create datasets that describe citywide urban canyon geometries.

We expect urban air temperature changes to be proportional to changes in canyon albedo. Since canyon albedo is related to the canyon geometry, it is important to define detailed urban geometries in UCMs to better simulate the urban climate. This study presented a method to scale previously obtained air temperature changes that were simulated using UCMs defined with generic canyon geometries. The method describes how to calculate scaling factors for the temperature changes specific to urban geometry, location, and season.

437 The first step for calculating scaling factors is using the proposed UCAM to calculate the downward solar 438 flux entering the canyon and the upward flux exiting the canyon. The canyon albedo can then be obtained as the ratio of upward to downward solar flux. We introduce the concept of canyon transmittance to describe the ability of a street inside a canyon to increase the reflection of sunlight through the canyon ceiling upon raising the albedo of the street. The proposed UCAM is used to calculate canyon transmittances. Finally, a scaling factor is then obtained as the ratio of canyon transmittances (transmittance from canyon of interest to transmittance of canyon used in climate model).

To demonstrate the physics behind a scaling factor, we compared the change in solar flux reflected from the simple narrow (no setbacks) canyon to that of the simple wide (with setbacks) canyon when raising the street albedo by 0.30 . The street in each canyon was $10 \mathrm{~m}$ wide, and the setbacks in the simple wide canyon were $10 \mathrm{~m}$ wide. Each wall in both canyons was also $10 \mathrm{~m}$ high. The simple wide canyon was able to reflect from 2.90 (summer) to 4.52 (fall) times more solar flux than the simple narrow canyon. These multipliers are the scaling factors for adjusting air temperature changes obtained with the simple narrow canyon to the simple wide canyon.

As a case study, we showed how to scale simulated air temperature changes obtained from modeling cool streets in Sacramento with WRF/urban canyon model. First, we defined the NLCD narrow canyon following the default geometry defined in the "high-intensity residential" land-use category described in the NLCD. Ten realistic wide canyons were also defined using 10 building prototypes as well as street design guidelines of Sacramento. We calculated seasonal values of canyon transmittance $\tau_{\text {canyon }}$ for each canyon. The seasonal $\tau_{\text {canyon }}$ of the NLCD narrow canyon ranged from 0.21 (winter) to 0.33 (summer). The large office canyon had tall walls $(H / W=0.93)$ and its canyon transmittances were similar to those of the NLCD narrow canyon. However, the canyon transmittances associated with the singlefamily home canyon, the two restaurant canyons, the two retail store canyons, and the primary school canyon ranged from 0.85 (winter of single-family home canyon) to 0.99 (spring, summer, and fall of restaurant canyons). The seasonal scaling factors for each wide canyon were then obtained as the ratio of the wide canyon transmittance to the NLCD narrow canyon transmittance. With the exception of the large office canyon, scaling factors were smallest in summer and highest in winter.

Sacramento's building stock was mapped by building type to the 10 wide canyons. The seasonal citywide scaling factors were obtained by averaging the scaling factors, weighted by the number of buildings in Sacramento assigned to each wide canyon. Since residential buildings are the most common building 
type in the city, the citywide scaling factors are dominated by residential canyons. The seasonal citywide scaling factors were 3.64 (spring), 2.70 (summer), 3.71 (fall), and 3.89 (winter). Rounding results to two significant figures, this indicates that the air cooling effect of raising street albedo by 0.30 in Sacramento is about 2.7 (summer) to 4.0 (winter) times that which was simulated with a narrow-canyon urban

472 climate model.

473 Including spatial variations in urban canyon geometry could improve future studies of urban climate, especially those exploring the consequences of changes to the thermophysical properties of the canyon. While the NUDAPT dataset is an important initial effort for defining realistic urban geometries, we suggest that future research should develop urban canyon geometrical datasets for cities worldwide that accurately represent the street and setbacks of the canyon floor. These datasets could then be used in WRF/urban models for studies of urban climate. For existing climate model results, the method presented in this study provides a solution to scale the modeled air temperatures without the need to repeat computationally expensive climate simulations.

\section{Acknowledgements}

The authors thank Krzysztof Fortuniak for providing the canyon albedo values presented in Fortuniak (2008). We also thank Courtney Smith, formerly of the California Air Resources Board; Mark Modera, University of California at Davis; Haider Taha, Altostratus, Inc.; Donna Chralowicz, City of San Diego; Yvonne Hunter, Institute of Local Governments; Jan Kleissl, University of California at San Diego; Ash Lashgari, California Air Resources Board; Bill Dean, California Environmental Protection Agency Office; Matt Machado, Stanislaus County; Eric Masanet, Northwestern University; Craig Tranby, Los Angeles Department of Water and Power; and Tom Van Dam, NCE. This project was funded by the California Air Resources Board under Contract 10-321. It was also supported by the Assistant Secretary for Energy Efficiency and Renewable Energy, Office of Building Technology, State, and Community Programs, of the U.S. Department of Energy under Contract No. DE-AC02-05CH11231.

\section{A Calculating solar fluxes and canyon albedo}

\section{A.1 Overview}

We present a three-reflection urban canyon albedo model (UCAM). A three-reflection model is one that tracks up to three reflections from canyon surfaces. The model considers the canyon as of infinite length and can be oriented either north-south (N-S) or east-west (E-W). The canyon model assumes the floor as has a central street surrounded by setbacks. The dimensions and albedos of the canyon surfaces (street, setback, and walls) can be varied. The model also considers shadows cast by the canyon walls. The air between the surfaces is assumed to neither absorb nor scatter light, and all surfaces are treated as Lambertian (purely diffuse) reflectors.

\section{A.2 Shadow on canyon floor}

During the day, the canyon floor may be partially or completely shaded by the canyon walls. The width of the canyon $w_{\mathrm{c}}$ is equal to the street width $w_{\mathrm{st}}$ plus twice the setback width $w_{\mathrm{sb}}$. The width of the canyon floor shadow, $w_{\mathrm{s}}$, depends on sun position and canyon orientation. To illustrate, Figure A-1 shows the shadow cast by a $10 \mathrm{~m}$ high wall over a $30 \mathrm{~m}$ wide floor (10 m street + two $10 \mathrm{~m}$ setbacks) in 
Sacramento, CA on October 21 at 08:00 local standard time (LST). The street extends N-S (panel a) and 508 E-W (panel b).

509

(a)

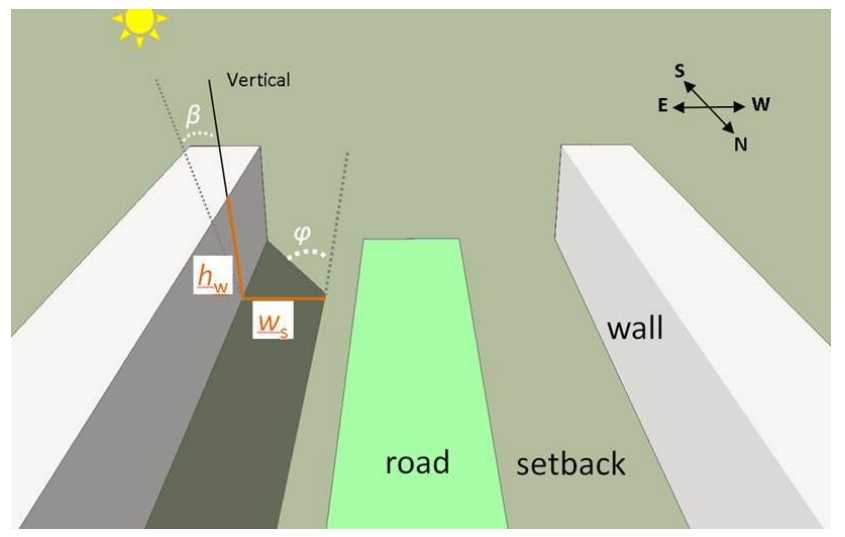

(b)

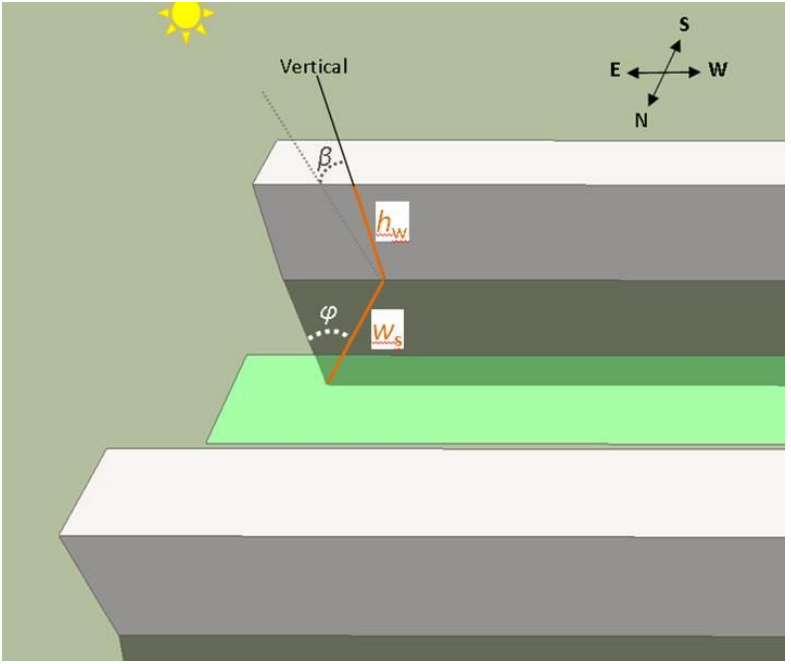

510

511

512

513

Figure A-1. Illustration of a wide canyon located in Sacramento, California, on October 21 at 8:00 LST. The canyon is oriented (a) N-S and (b) E-W. The street width, setback width, and wall height are $10 \mathrm{~m}$ each. The variables shown are canyon width $\left(w_{\mathrm{s}}\right)$, wall height $\left(h_{\mathrm{w}}\right)$, azimuth angle $(\phi)$, and zenith angle $(\beta)$.

When the canyon runs N-S,

$$
w_{\mathrm{s}}=h_{\mathrm{w}} \tan \beta \sin \phi
$$

514 where $h_{\mathrm{w}}$ is the height of the wall, $\beta$ is the solar zenith angle, and $\phi$ is the solar azimuth angle 515 (measured clockwise from south).

516 When the canyon runs E-W,

$$
w_{\mathrm{s}}=h_{\mathrm{w}} \tan \beta \cos \phi \text {. }
$$

517 When the shadow is wider than the canyon, the wall facing the sun may be partially shaded by the other 518 wall. The height of the shaded portion $h_{\mathrm{s}}$ is

$$
h_{\mathrm{s}}=\frac{h_{\mathrm{w}}\left(w_{\mathrm{s}}-w_{\mathrm{c}}\right)}{w_{\mathrm{s}}}
$$

and the height of the unshaded portion $h_{\mathrm{u}}$ is

$$
h_{\mathrm{u}}=h_{\mathrm{w}}-h_{\mathrm{s}}
$$

\section{A.3 Calculating solar fluxes}

521 The model calculates the flux that enters the canyon and is intercepted by the walls and floor. It takes as 522 inputs global horizontal irradiance $I_{\mathrm{g}}\left[\mathrm{W} / \mathrm{m}^{2}\right]$ and diffuse horizontal irradiance $I_{\mathrm{d}}\left[\mathrm{W} / \mathrm{m}^{2}\right]$. Annual hourly 523 mean global and diffuse horizontal irradiances are available for over 1,000 sites in the United States 
524 from the National Renewable Energy Laboratory's Typical Meteorological Year, version 3 (TMY3) data 525 sets (Wilcox and Marion 2008). The beam (a.k.a. direct) horizontal irradiance $I_{\mathrm{b}}$ is then calculated as

$$
I_{\mathrm{b}}=I_{\mathrm{g}}-I_{\mathrm{d}}
$$

526 and the beam normal solar irradiance $I_{\mathrm{bn}}$ is

$$
I_{\mathrm{bn}}=\frac{I_{\mathrm{b}}}{\cos \beta} .
$$

527 Using these solar irradiances and the algorithm detailed next, the model can then calculate the flux that 528 is reflected from the canyon through the ceiling, and calculate the canyon albedo.

$529 \quad$ A.3.1 Downward diffuse solar flux intercepted by the canyon surfaces

530 The diffuse solar flux entering through the ceiling is

$$
J_{2}=I_{\mathrm{d}} w_{\mathrm{c}} .
$$

531 The fraction of $J_{2}$ that strikes a floor segment is

$$
J_{2 \rightarrow 0}=J_{2} F_{2 \rightarrow 0}
$$

532 where $F_{2 \rightarrow 0}$ is the view factor to a floor segment from the canyon ceiling. The model iterates through 533 the segments to obtain each value of $J_{2 \rightarrow 0}$.

534 The fractions of $J_{2}$ that are intercepted by the left wall $J_{2 \rightarrow 3}$ and by the right wall $J_{2 \rightarrow 4}$ are

$$
J_{2 \rightarrow 3}=J_{2} F_{2 \rightarrow 3}
$$

535 and

$$
J_{2 \rightarrow 4}=J_{2} F_{2 \rightarrow 4}
$$

536 where $F_{2 \rightarrow 3}$ and $F_{2 \rightarrow 4}$ are the view factors from ceiling to left wall and from ceiling to right wall, 537 respectively.

$538 \quad$ A.3.2 Downward beam solar flux intercepted by the canyon surfaces

539 When a floor segment is unshaded, the beam flux from the solar disc intercepted by the segment is

$$
J_{5 \rightarrow 0}=I_{\mathrm{b}} w_{0}
$$

540 The model compares the shadow width $\left(w_{\mathrm{s}}\right)$ to the segment's distance from each canyon wall to

541 determine whether the segment is unshaded. If segment is in shade, $J_{5 \rightarrow 0}=0$. The model iterates

542 through the segments to obtain each value of $J_{5 \rightarrow 0}$.

543 The ASHRAE Handbook-Fundamentals (ASHRAE 2009) details how to calculate the downward beam 
solar irradiance incident on a tilted surface $I_{\mathrm{t}, \mathrm{b}}$. Let $\theta$ represent angle of incidence. For vertical 545 surfaces (tilt angle $90^{\circ}$ ) such as walls, the beam tilt irradiance is

$$
I_{\mathrm{t}, \mathrm{b}}=I_{\mathrm{bn}} \cos \theta
$$

546 when $\cos \theta>0$; otherwise, the surface is in shade. The wall may also be partially or fully shaded by the 547 opposite wall at certain times of the day. For walls or section of walls that are in shade, $I_{\mathrm{t}, \mathrm{b}}=0$.

548 The cosine of the incidence angle is

$$
\cos \theta=\cos \left(90^{\circ}-\beta\right) \cos (\phi-\Psi)
$$

549 550

where $\Psi$ is the surface azimuth angle. Thus the beam flux to the unshaded section of wall $k$ from the sun (surface 5 ) is

$$
J_{5 \rightarrow k \mathrm{u}}=I_{\mathrm{t}, \mathrm{b}} h_{k \mathrm{u}} \cos \theta_{k}
$$
where $h_{k \mathrm{u}}$ is the height of the unshaded portion of wall $k$ and $\theta_{k}$ is the angle of incidence for wall $k$. 552 This equation yields the fluxes from the sun to the unshaded portion of the left wall, $J_{5 \rightarrow 3 u}$, with 553 unshaded height $h_{3 \mathrm{u}}$; and to the unshaded portion of the right wall, $J_{5 \rightarrow 4 \mathrm{u}}$, with unshaded height $h_{4 \mathrm{u}}$.

554 The magnitudes of $J_{5 \rightarrow 0}, J_{5 \rightarrow 3 u}$, and $J_{5 \rightarrow 4 u}$ depend on wall orientation and solar position. For example, an urban canyon whose length extends $\mathrm{E}-\mathrm{W}$ has one wall facing north (surface azimuth angle of $180^{\circ}$ ) and the other facing south $\left(0^{\circ}\right)$. For canyons whose length extends $\mathrm{N}-\mathrm{S}$, one wall faces east $\left(-90^{\circ}\right)$ and the other faces west $\left(90^{\circ}\right)$. Solar position (zenith and azimuth angles) can be obtained from NREL's Solar Position Calculator (NREL 2013) by location, date, and time, or computed following ASHRAE (2009).

\section{A.3.3}

\section{Example of calculating the canyon-reflected solar fluxes}

560 The albedo $\rho_{\mathrm{X}}$ is the fraction of the incoming flux that is reflected from canyon surface $\mathrm{X}$. The view factor $F_{X \rightarrow Y}$ is the fraction of the reflected flux leaving surface $X$ that is intercepted by surface $Y$. Using the albedo of every canyon surface and the view factors from each surface to all other surfaces, we calculated all of the fluxes that are listed in Table 1 through Table 3. As an example, the tworeflection flux from the sun (surface 5 ) to a floor segment (0) to the left wall (3) to the canyon ceiling (2) is

$$
J_{5 \rightarrow 0 \rightarrow 3 \rightarrow 2}=J_{5 \rightarrow 0} \rho_{0} F_{0 \rightarrow 3} \rho_{3} F_{3 \rightarrow 2} .
$$

566 This approach was used to calculate all one-, two-, and three-reflection fluxes.

\section{$567 \quad$ A.4 Canyon albedo}

568 For the three-reflection proposed UCAM, the upward flux leaving the canyon, $J_{\text {up }}$, is the sum of all 569 fluxes listed in Table 1, Table 2, and Table 3, including all fluxes that are intercepted by each floor 570 segment. The downward flux entering the canyon is

$$
J_{\text {down }}=w_{2} I_{\mathrm{g}}
$$


571 where $w_{2}$ is the width of the canyon ceiling. Hence, the canyon albedo $\rho_{\mathrm{c}}$ is the ratio of upward flux to

572 downward flux:

$$
\rho_{\mathrm{c}} \equiv \frac{J_{\text {up }}}{J_{\text {down }}}
$$

573 The daily mean canyon albedo is

$$
\bar{\rho}_{\mathrm{c}}=\frac{\int_{\text {day }} J_{\text {down }}(t) \rho_{\mathrm{c}}(t) d t}{\int_{\text {day }} J_{\text {down }}(t) d t}
$$

$574 \quad$ where $t$ is time.

\section{B View factor calculations}

576 View factor formulas have been presented in the engineering literature for most common geometric 577 configurations (Howell 2015). All the view factors required in the proposed UCAM can be calculated 578 from published formulas.

\section{$579 \quad$ B.1 Ceiling to wall}

580 Consider two infinitely long perpendicular plates sharing a common edge (e.g. the geometry formed by the canyon ceiling and a canyon wall in Figure $\mathrm{A}-1$ ). If horizontal surface $\mathrm{X}$ has width $w$ and vertical surface $\mathrm{Y}$ has height $h$, the view factor to $\mathrm{Y}$ from $\mathrm{X}$ is

$$
F_{\mathrm{X} \rightarrow \mathrm{Y}}=\frac{1}{2}\left(1+\frac{h}{w}-\sqrt{1+\left(\frac{h}{w}\right)^{2}}\right) .
$$

(Howell 2015, Equation C-3). This formula yields the view factors from the canyon ceiling (surface 2, width $w_{2}$ ) to the entire left wall (surface 3 , height $h_{3}$ ); to the entire right wall (surface 4 , height $h_{4}$ ); to the unshaded portion of the left wall (surface $3 u$, height $h_{3 u}$ ); and to the unshaded portion of the right

View factor reciprocity relates view factors $(F)$ and areas $(A)$, such that

$$
A_{\mathrm{X}} F_{\mathrm{X} \rightarrow \mathrm{Y}}=A_{\mathrm{Y}} F_{\mathrm{Y} \rightarrow \mathrm{X}} \text {. }
$$

589 View factors $F_{3 \rightarrow 2}, F_{4 \rightarrow 2}, F_{3 \mathrm{u} \rightarrow 2}$, and $F_{4 \mathrm{u} \rightarrow 2}$ can be obtained from this relation.

\section{$590 \quad$ B.2 Ceiling to floor}

591 The sum of view factors from a given surface to itself and all other surfaces is unity. Thus from the 592 canyon ceiling (surface 2),

$$
F_{2 \rightarrow 1}+F_{2 \rightarrow 2}+F_{2 \rightarrow 3}+F_{2 \rightarrow 4}=1 \text {. }
$$


By symmetry, $F_{2 \rightarrow 3}=F_{2 \rightarrow 4}$. Meanwhile, $F_{2 \rightarrow 2}$ is zero since the surface 2 does not see itself. Hence, the ceiling-to-floor view factor is

$$
F_{2 \rightarrow 1}=1-2 \times F_{2 \rightarrow 3} .
$$

\section{B.3 Segment to ceiling}

The view factor from a floor segment to sky varies by segment. As the model iterates through the segments, it calculates their view factor to the sky using the "crossed-string method" (Hottel 1954). Figure B-1 illustrates how the method is applied to calculate the segment-to-sky view factor. The model calculates the distances $L_{x}, L_{w}, L_{y}$, and $L_{z}$ for each segment.

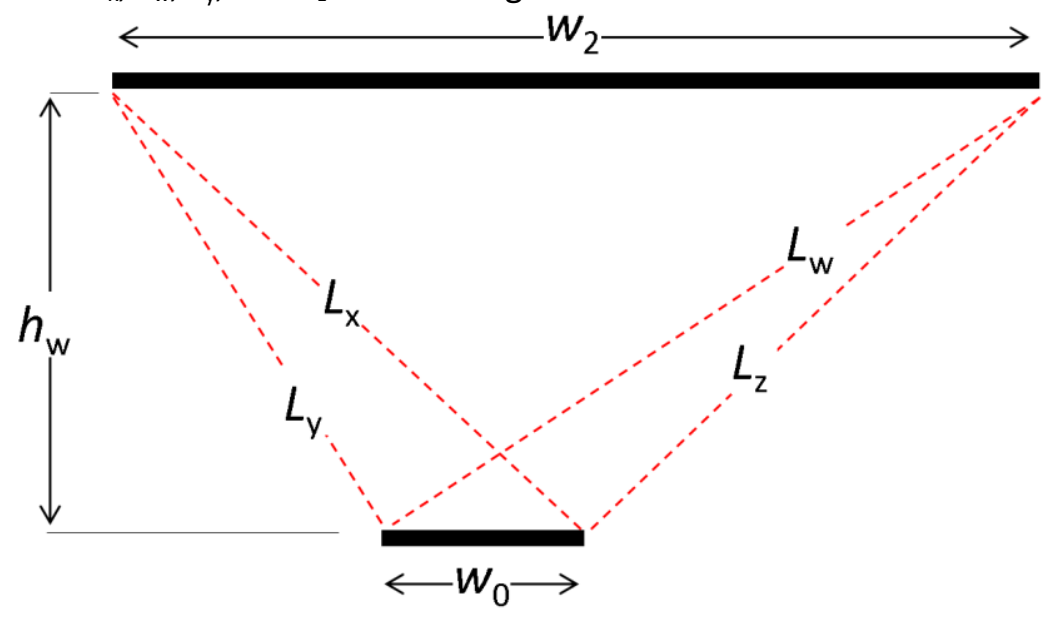

600 Figure B-1. Crossed-string method applied to segment-to-ceiling view factors.

601 The equation (Howell 2015, section C-2a) is derived from this method and used to calculate the 602 segment-to-ceiling view factors:

$$
F_{0 \rightarrow 2}=\frac{L_{\mathrm{x}}+L_{\mathrm{w}}-L_{\mathrm{y}}-L_{\mathrm{z}}}{2 w_{0}}
$$

\section{B.4 Segment to wall}

604 Consider an infinitely long plate $S_{1}$ at an angle $\alpha$ from another non-adjacent infinitely long plate $S_{2}$. If the 605 plates are perpendicular, the formula for this configuration (Figure B-2a) can be simplified to

$$
F_{S_{1} \rightarrow S_{2}}=\frac{\left(a_{1}^{2}-b_{2}^{2}\right)^{1 / 2}+\left(a_{2}^{2}+b_{1}^{2}\right)^{1 / 2}-\left(a_{2}^{2}+b_{2}^{2}\right)^{1 / 2}-\left(a_{1}^{2}+b_{1}^{2}\right)^{1 / 2}}{2\left(a_{2}-a_{1}\right)}
$$

606

607

608

(Howell 2015, section C-5a). This formula is used by the model to calculate the view factor from each wall to each floor segment. Given the position of the segment relative to each wall (Figure B-2b), $F_{3 \rightarrow 0}$, $F_{3 u \rightarrow 0}, F_{4 \rightarrow 0}$, and $F_{4 u \rightarrow 0}$ are calculated as follows:

$$
\begin{gathered}
F_{3 \rightarrow 0}=F_{S_{1} \rightarrow S_{2}}\left(a_{1}=0, a_{2}=h_{\mathrm{w}}, b_{1}=x_{1}, b_{2}=x_{2}\right) \\
F_{4 \rightarrow 0}=F_{S_{1} \rightarrow S_{2}}\left(a_{1}=0, a_{2}=h_{\mathrm{w}}, b_{1}=w_{\mathrm{c}}-x_{2}, b_{2}=w_{2}-x_{1}\right)
\end{gathered}
$$




$$
\begin{gathered}
F_{3 \mathrm{u} \rightarrow 0}=F_{S_{1} \rightarrow S_{2}}\left(a_{1}=h_{w}-h_{3 \mathrm{u}}, a_{2}=h_{\mathrm{w}}, b_{1}=x_{1}, b_{2}=x_{2}\right) \\
F_{4 \mathrm{u} \rightarrow 0}=F_{S_{1} \rightarrow S_{2}}\left(a_{1}=h_{w}-h_{4}, a_{2}=h_{\mathrm{w}}, b_{1}=w_{2}-x_{2}, b_{2}=w_{2}-x_{1}\right)
\end{gathered}
$$

609 Note that $x_{1}$ and $x_{2}$ vary by segment, while $h_{3 \mathrm{u}}$ and $h_{4 \mathrm{u}}$ vary by time of day.

(a)

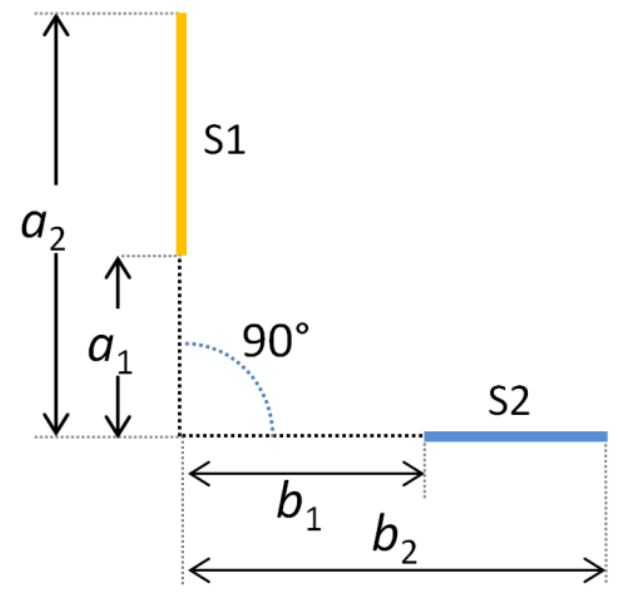

(b)

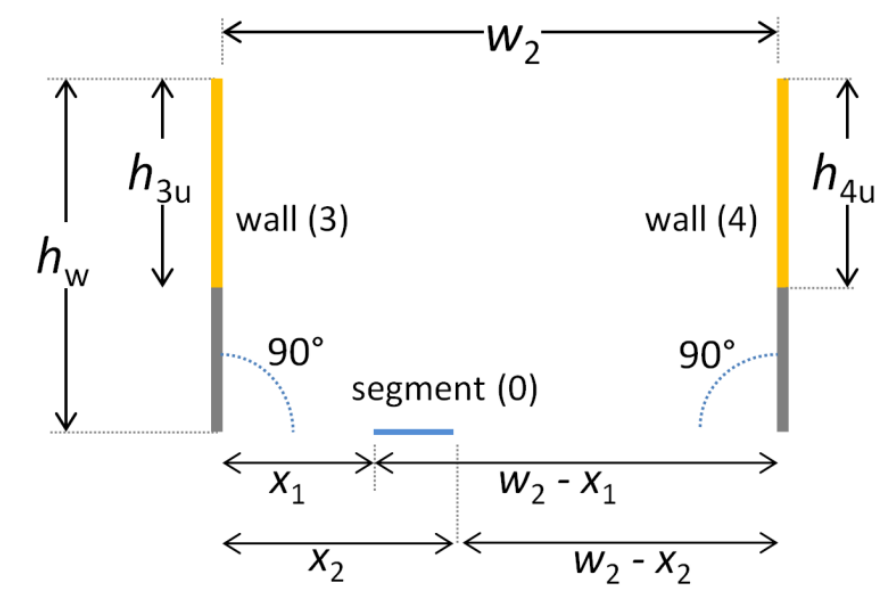

610 Figure B-2. Diagram of dimensions and variables used to calculate segment to wall view factors.

611 Applying view-factor reciprocity, segment-to-wall view factors are calculated as

$$
\begin{gathered}
F_{0 \rightarrow 3}=\frac{h_{3} F_{3 \rightarrow 0}}{w_{0}} \\
F_{0 \rightarrow 4}=\frac{h_{4} F_{4 \rightarrow 0}}{w_{0}} .
\end{gathered}
$$

\section{B.5 Wall to wall}

613 The "cross-string method" described in Section B.3 can also be used to calculate the view factors from 614 one wall (or section of wall) to the opposite wall (or section of opposite wall). Thus, Eq. (B-5) and the 615 canyon dimensions given in Figure B-2 were used to obtain the view factors from one canyon wall to the opposite wall $\left(F_{3 \rightarrow 4}\right.$ and $\left.F_{4 \rightarrow 3}\right)$, and from the unshaded portion of each wall to the opposite wall $\left(F_{3 u \rightarrow 4}\right.$

\section{References}

620 Arnfield AJ. 1988. Validation of an estimation model for urban surface albedo. Physical Geography 9(4), 621 361-372.

622 ASHRAE 2009. Chapter 14: Climatic Design Information. 2009 ASHRAE Handbook-Fundamentals (SI).

623 Best MJ, Grimmond CSB. 2015. Key Conclusions of the First International Urban Land Surface Model 624 Comparison Project. Bulletin of the American Meteorological Society 96(5), 805-819. 
625

Chen F, Kusaka H, Bornstein R, Ching J, Grimmond C, Grossman-Clark S, Loridan T, Manning K, Martilli A, Miao S, Sailor D, Salamanca F, Taha H, Tewari M, Wang X, Wyszogrodzki A, Zhang C. 2011. The integrated WRF/urban modelling system: development, evaluation, and applications to urban environmental problems. International Journal of Climatology 31, 273-288.

Chimklai P, Hagishima A, Tanimoto J. 2004. A computer system to support albedo calculation in urban areas. Building and Environment 39, 1213-1221.

Ching J, Brown M, Burian S, Chen F, Cionco R, Hanna A, Hultgren T, McPherson T, Sailor D, Taha H, and Williams D. 2009. National Urban Database and Access Portal Tool, NUDAPT. Bulletin of the American Meteorological Society 90, 1157-1168.

Davies JA, Schertzer W, Nunez M. 1975. Estimating global solar radiation. Boundary-Layer Meteorology 9, 33-52.

Deru M, Field K, Studer D, Benne K, Griffith B, Torcellini P, Liu B, Halverson M, Winiarski D, Rosenberg M, Yazdanian M, Huang J, Crawley D. 2011. US Department of Energy commercial reference building models of the national building stock. Technical report NREL/TP-5500-46861. National Renewable Energy Laboratory, Golden, CO. http://energy.gov/eere/buildings/commercial-reference-buildings

EERE. 2014. Building Energy Codes Program - Residential Prototype Building Models. May 2014. https://www.energycodes.gov/development/residential/iecc_models

Fortuniak K. 2008. Numerical estimation of the effective albedo of an urban canyon. Theoretical and Applied Climatology 91, 245-258.

Harman IN, Best MJ, Belcher SE. 2004. Radiative exchange in an urban street canyon. Boundary-Layer Meteorology 110, 301-316.

HIG. 2016. Heat Island Group, Lawrence Berkeley National Laboratory. Berkeley, CA. Retrieved 2016-0701 from http://Heatlsland.LBL.gov.

Homer C.G., Dewitz J.A., Yang L, Jin S, Danielson P, Xian G, Coulston J, Herold ND, Wickham JD, and Megown K. 2015. Completion of the 2011 National Land Cover Database for the conterminous United States-Representing a decade of land cover change information. Photogrammetric Engineering and Remote Sensing 81(5), 345-354.

Hottel, HC. 1954. Radiant Heat Transmission. William H. McAdams 3rd Edition. pp 55-125. McGraw-Hill Book Co., New York.

Howell JR. 2015. A catalog of radiation configuration factors. McGraw-Hill Book Co., New York. Retrieved 2015-12-10 from http://www.thermalradiation.net/tablecon.html

Kusaka H, Kondo H, Kikegawa Y, Kimura F. 2001. A simple single-layer urban canopy model for atmospheric models: comparison with multi-layer and slab models. Boundary-Layer Meteorology 101, 329-358.

Kusaka H, Kimura F. 2004. Coupling a single-layer urban canopy model with a simple atmospheric model: impact on urban heat island simulation for an idealized case. Journal of the Meteorological Society of Japan 82(1), 67-80.

Ichinose T, Shimodozono K, Hanaki K. 1999. Impact of anthropogenic heat on urban climate in Tokyo. Atmospheric Environment 33, 3897-3909.

Li D, Bou-Zeid E, Oppenheimer M. 2014. The effectiveness of cool and green roofs as urban heat island mitigation strategies. Environmental Research Letters 9(5), 055002 (16 pages). 
Martilli A, Clappier A, Rotach MW. 2002. An urban surface exchange parameterization for mesoscale models. Boundary-Layer Meteorology 104, 261-304.

668 Masson V. 2000. A physically-based scheme for the urban energy budget in atmospheric models. 669 Boundary-Layer Meteorology 94, 357-397.

670 Mohegh A, Rosado P, Jin L, Millstein D, Levinson R, Ban-Weiss G. (submitted). Modeling the climate 671 impacts of deploying solar reflective cool pavements in California cities. Submitted to Journal Name.

672 NREL. 2013. Measurement and Instrumentation Data Center Solar Position (SOLPOS) Calculator.

673 National Renewable Energy Laboratory, Golden, CO. Retrieved 2015-12-10 from 674 http://www.nrel.gov/midc/solpos/spa.html

675 PNNL. 2014. Residential Prototype Building Models. Pacific Northwest National Laboratory, Richland, 676 WA. Retrieved 2015-12-10 from https://www.energycodes.gov/development/residential/iecc_models

677 Public Records. 2015. Public Records, Assessor's Office, Sacramento County. December 2015. 678 http://www.assessor.saccounty.net/MapsPropertyDataAndRecords/Pages/Assessor'sRecords.aspx

679 Sacramento Street Design Standards. 2009. Design and Procedures Manual: Section 15 - Street Design 680 Standards. City of Sacramento CA. Retrieved 2015-12-10 from 681 http://portal.cityofsacramento.org/Public-Works/Resources/Publications

682 Skamarock WC, Klemp JB, Dudhia J, Gill DO, Barker DM, Duda MG, Huang XY, Wang W, Powers JG. 2008. 683 A description of the advanced research WRF version 3. NCAR Tech. Note NCAR/TN 475 STR, 125, 684 National Center for Atmospheric Research, Boulder, CO. Retrieved 2015-12-10 from http://www2.mmm.ucar.edu/wrf/users/docs/arw_v3.pdf

688 Tsangrassoulis A, Santamouris M. 2003. Numerical estimation of street canyon albedo consisting of 689 vertical coated glazed facades. Building Environment 35, 527-531.

690 Terjung WH, Louie S. 1973. Solar radiation and urban heat islands. Annals of the Association of American 691 Geographers 63(2), 181-207.

692 Vahmani P, Ban-Weiss GA. 2016. Impact of remotely sensed albedo and vegetation fraction on 693 simulation of urban climate in WRF-urban canopy model: A case study of the urban heat island in Los 694 Angeles. Journal of Geophysical Research: Atmospheres 121(4), 1511-1531.

695 Wang ZH, Bou-Zeid E, Smith JA. 2013. A coupled energy transport and hydrological model for urban canopies evaluated using a wireless sensor network. Quarterly Journal of the Royal Meteorological Society 139(675), 1643-1657.

Wilcox S, Marion W. 2008. User's Manual for TMY3 Data Sets, NREL/TP-581-43156. National Renewable Energy Laboratory, Golden CO. Retrieved 2015-12-10 from http://rredc.nrel.gov/solar/old_data/nsrdb/1991-2005/tmy3

701 Yang J, Wang ZH, Chen F, Miao S, Tewari M, Voogt JA, Myint S. 2015. Enhancing hydrologic modelling in 702 the coupled Weather Research and Forecasting-urban modelling system. Boundary-Layer Meteorology 703 155(1), 87-109.

704 ZCSC. 2015. Sacramento County Zoning Code. Sacramento County, CA. Retrieved 2015-12-10 from 705 http://www.per.saccounty.net/LandUseRegulationDocuments/Pages/Sacramento\%20County\%20Zoning $706 \% 20$ Code.aspx 